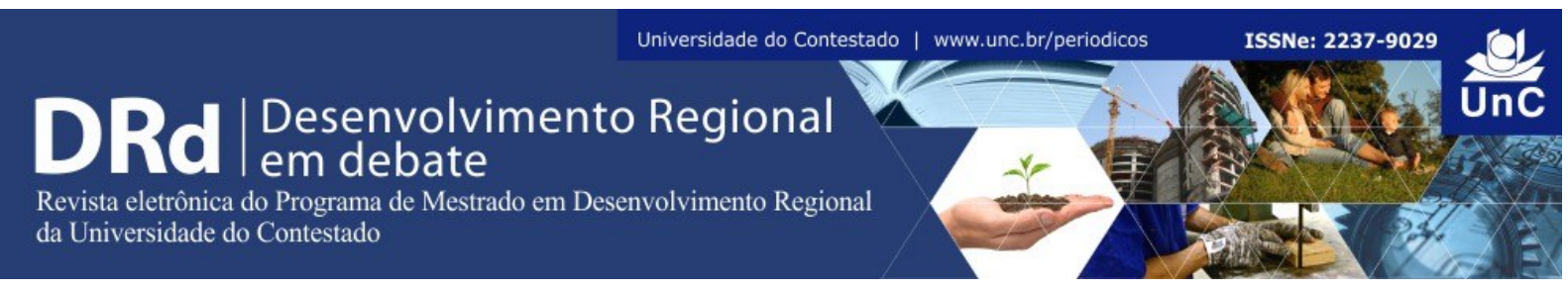

\title{
CONSTRUÇÃO E ANÁLISE DO ÍNDICE DE DESENVOLVIMENTO RURAL PARA AS MESORREGIÕES NORTE E JEQUITINHONHA DO ESTADO DE MINAS GERAIS
}

\author{
Rosimere Miranda Fortini ${ }^{1}$ \\ Suely de Fátima Ramos Silveira ${ }^{2}$ \\ Vinicius de Souza Moreira ${ }^{3}$
}

\section{RESUMO}

O objetivo deste estudo foi desenvolver e analisar um índice de desenvolvimento rural (IDR) para as mesorregiões Norte de Minas e Jequitinhonha, buscando (i) caracterizar o meio rural das regiões estudadas; (ii) identificar e analisar as variáveis para a construção do índice; e (iii) construir um indicador sintético do desenvolvimento rural, para as mesorregiões estudadas. Os dados da pesquisa foram obtidos por meio da aplicação de questionários aos agricultores familiares nas mesorregiões Norte de Minas e Jequitinhonha, totalizando 17 municípios visitados e 216 entrevistados. A fim de atingir o objetivo proposto, os dados foram analisados tendo como base procedimentos estatísticos manipulados nos programas Statistical Package for the Social Sciences (SPSS) v. 20.0® e MS Excel. Fez-se uso da estatística descritiva e da representação gráfica, gerando o diagrama de caixas (boxplot) e histogramas. O IDR sintetiza quatro indicadores considerando as dimensões social, econômica, ambiental e apropriação tecnológica. De modo geral, o IDR encontrou-se entre os níveis de desenvolvimento de baixo a moderado. Os indicadores que integraram o IDR concentraram-se em níveis baixos, sendo necessária a atuação do governo em todas as dimensões analisadas para que um número maior de agricultores familiares alcance níveis de desenvolvimento rural mais elevados. A análise por índices fornece informações para decisões sobre políticas públicas e indicam a necessidade de efetiva atuação governamental - seja concedendo subsídios, incentivos, crédito e assistência técnica -, de modo a consolidar o desenvolvimento rural sustentável nas mesorregiões Norte de Minas e Jequitinhonha.

Palavras-chave: Agricultura Familiar. Desenvolvimento Rural. Índice de Desenvolvimento Rural.

\footnotetext{
${ }^{1}$ Graduação em Ciências Econômicas. Universidade Federal de Viçosa. Viçosa. Minas Gerais. Brasil. E-mail: rosifortini@gmail.com

${ }^{2}$ Doutorado em Economia Aplicada. Professora do Programa de Pós-Graduação em Administração da Universidade Federal de Viçosa (UFV) e atual Diretora do Instituto de Políticas Públicas e Desenvolvimento Sustentável - IPPDS. Universidade Federal de Viçosa. Viçosa. Minas Gerais. Brasil. E-mail: sramos@ufv.br

${ }^{3}$ Mestrado pelo programa de Pós-Graduação em Administração. Universidade Federal de Viçosa. Viçosa. Minas Gerais. Brasil. E-mail: vinicius.souza@ufv.br
}

DRd - Desenvolvimento Regional em debate (ISSNe 2237-9029) 


\title{
CONSTRUCTION AND ANALYSIS OF RURAL DEVELOPMENT INDEX FOR THE MESO-REGIONS NORTH AND JEQUITINHONHA IN MINAS GERAIS
}

\begin{abstract}
The objective of this study was to develop and analyze a rural development index for the mesoregions North of Minas Gerais and Jequitinhonha, seeking (i) characterize the countryside of the studied regions; (ii) identify and analyze the variables for the construction of the index; and (iii) build a synthetic indicator of rural development for the studied mining mesoregions. Survey data were obtained through questionnaires with family farmers in mining mesoregions North of Minas Gerais and Jequitinhonha, totaling 17 municipalities visited and 216 respondents. In order to achieve the objective proposed by this study, data were analyzed using statistical procedures handled in the Statistical Package for Social Sciences (SPSS) v. 20.0® and MS Excel. There was use of descriptive statistics and graphical representation, generating boxes diagram (boxplot) and histograms. In general, the IDR was found between low to moderate levels of development. The indicators that were part of the IDR, focused on low levels evenly, requiring the government action in all extensions (social, economic, environmental and technological appropriation) so that a larger number of farmers reach levels of rural development higher. Therefore, such information is necessary for the government to act in order to be effectively subsidies, incentives, public policies - in order to consolidate the prosperous rural development in meso North of Minas Gerais and Jequitinhonha.
\end{abstract}

Keywords: Family farming. Rural development. Rural Development Index.

\section{INTRODUÇÃO}

O meio rural brasileiro é caracterizado por um conjunto distinto de atributos que estão relacionados à diversidade de ambientes físicos, recursos naturais, agroecossistemas, sistemas agrários, etnias, culturas, padrões tecnológicos, formas de organização social e política, e linguagens (SILVA et al., 2009).

Helfand (1999) afirma que este é um espaço que além de viabilizar novas estratégias de conservação ambientais combinadas à produção sustentável, deve promover e estimular a inclusão social e a promoção da igualdade, gerando alternativas tecnológicas que beneficiem o desenvolvimento dos agricultores familiares.

No cenário agrícola, os agricultores familiares adotam diferentes estratégias de sobrevivência e produção para desenvolverem suas atividades. Todavia, é imprescindível a ação governamental por meio de políticas públicas conjuntas para preencher as lacunas sociais, econômicas, culturais e políticas existentes para o segmento. Com tal intuito, é importante compreender o meio em que vivem os agricultores familiares.

Pela sua relevância, pesquisadores dedicam-se em estudos para compreensão do desenvolvimento do meio rural. Em comum, esses pesquisadores elaboraram Índices de Desenvolvimento Rural (IDR), podendo citar os estudos da Kageyama (1996, 2003, 2004, 
2006 e 2008), Maluf, Mattei e Lins (2006), Melo e Parré (2007), Conterato (2008), Orsi (2009), Arruda (2010), Stege (2011), Canodá (2013). Outros estudos como os de Moreira, Silveira e Motter (2014) e Waquil et al. (2015) apresentaram índices de satisfação (renda, produção e qualidade de vida) e o Índice de Condições de Vida (ICV) aplicados a territórios rurais, respectivamente. Por outro lado, percebe-se que as pesquisas utilizam diferentes variáveis e territórios considerando diferentes períodos, proporcionando análises de resultados mais específicas.

Segundo Veiga (2001), os elementos-chave para o desenvolvimento rural sustentável no Brasil referem-se à valorização e ao fortalecimento da agricultura familiar, à diversificação das economias e ao estímulo ao empreendedorismo local por meio de incentivos provenientes do Estado, destinados à formação de arranjos institucionais locais. Exemplos de arranjos institucionais são: estados, mercados, redes, associações e comunidades, ou seja, arranjos que além de serem institucionalizados, são compostos de diferentes instituições e organizações (NORONHA; TURCHI, 2005).

No Censo Agropecuário de 2006 (BRASIL, 2009) foram identificados 4.367 .902 estabelecimentos de agricultores familiares, o que representa $84,4 \%$ dos estabelecimentos rurais brasileiros. Este contingente ocupava área de 80,25 milhões de hectares, ou seja, 24,3\% da área ocupada por todos os estabelecimentos agropecuários do país. Tais resultados revelam uma estrutura agrária concentrada: os estabelecimentos não familiares, apesar de representarem $15,6 \%$ do total dos estabelecimentos, abarcam $75,7 \%$ da área ocupada (BRASIL, 2009).

Mesmo ocupando menor extensão territorial, a agricultura familiar emprega cerca de cinco milhões de famílias, sendo responsável pela maioria dos alimentos que chegam à mesa dos brasileiros, como o leite (58\%), mandioca (83\%) e o feijão (70\%) (BRASIL, 2014). Desse modo, a agricultura familiar destaca-se como um dos setores da economia que mais colabora na produção de alimentos direcionados ao abastecimento nacional, na ocupação da mão de obra e geração de renda, além de representar potencial para promoção do desenvolvimento rural sustentável.

Entre os entes federativos, Minas Gerais é o segundo estado brasileiro que possui maior número de estabelecimentos rurais enquadrados como familiares, totalizando 437.415 propriedades, responsáveis por $32 \%$ da produção de café, $49 \%$ de feijão, $32 \%$ de arroz, $44 \%$ de milho e $83 \%$ de toda a produção de mandioca do país (MINAS GERAIS, 2014). Por essa relevância nota-se a importância da agricultura familiar para a promoção do desenvolvimento rural do referido estado.

Neste sentido, como recorte geográfico para base do estudo, selecionou-se duas mesorregiões do estado mineiro que juntas concentram 34,5\% de agricultores familiares em situação de pobreza: as regiões Norte de Minas e Jequitinhonha (MINAS GERAIS, 2014). Os agricultores familiares em situação de pobreza possuem renda familiar bruta anual de até R\$ 20.000,00, conforme as normas do Plano Safra 2013/2014, sendo caracterizados pela 
vulnerabilidade econômica e dependência de auxílios e/ou subsídios governamentais ${ }^{4}$ para desenvolverem suas atividades cotidianas (BRASIL, 2013).

Assim, a questão de pesquisa por trás do contexto supracitado é: qual é o nível de desenvolvimento rural das mesorregiões Norte de Minas e Jequitinhonha?

Como forma de responder ao questionamento norteador da investigação, traçou-se como objetivo o delineamento e análise de um índice de desenvolvimento rural para as mesorregiões Norte de Minas e Jequitinhonha buscando (i) caracterizar o meio rural das regiões estudadas; (ii) identificar e analisar as variáveis para a construção do índice; e (iii) construir um indicador sintético do desenvolvimento rural, para as mesorregiões estudadas.

Compreender como se encontram e quais são as principais características dos municípios das mesorregiões mineiras Norte de Minas e Jequitinhonha quanto ao seu desenvolvimento se mostra importante para que, a partir da construção dos indicadores sintéticos, se possa contribuir com a discussão sobre estratégias de desenvolvimento moldadas às necessidades regionais. Neste perspectiva, a contribuição do estudo está na construção de um IDR, a partir de um estudo empírico, sendo que a elaboração baseou-se nos dados coletados por meio da interrogação direta aos agricultores familiares. Logo, trata-se de um índice de desenvolvimento rural que leva em consideração a perspectiva do entrevistado.

Além desta parte introdutória, o estudo encontra-se dividido em: referencial teórico, abordando os principais aspectos da literatura sobre o Desenvolvimento Rural e o Índice de Desenvolvimento Rural; procedimentos metodológicos, indicando o percurso adotado para cumprimento dos objetivos de pesquisa; análise e interpretação dos resultados; e, para finalizar, as principais conclusões sobre a investigação realizada.

\section{DESENVOLVIMENTO RURAL}

O processo de desenvolvimento é inerente a evolução das sociedades e das nações, mas o termo "desenvolvimento econômico" emergiu somente no século XX. Nos séculos anteriores, a preocupação era com a acumulação de capital para aumentar o poder econômico e militar. Neste contexto, a preocupação com a melhoria da qualidade de vida da população era escassa.

Acontecimentos marcantes na sociedade mundial, como o surgimento do Estado Nacional Moderno, o Renascimento e as grandes descobertas marítimas revolucionaram as relações econômicas, promovendo mudanças no plano social e na forma de se pensar o desenvolvimento (SOUZA, 2005).

\footnotetext{
${ }^{4}$ Os auxílios/subsídios governamentais comumente direcionados ao pública rural são: o Bolsa Família, aposentadoria rural, Garantia Safra, Programa de Aquisição de Alimentos (PAA), Programa Nacional de Fortalecimento da Agricultura Familiar (PRONAF), entre outros.
} 
Embora não exista uma definição universalmente aceita para o termo desenvolvimento e este possa ser analisado sob variados pontos de vista, diversos autores versam sobre a referida temática.

Souza (1995) aponta para a existência de duas correntes de pensamento econômico sobre o desenvolvimento. A primeira corrente de economistas - de inspiração mais teórica -, entende o desenvolvimento como sinônimo de crescimento, podendo citar os modelos de crescimento da tradição clássica e neoclássica, como os de Harrod, de 1939, e Domar, de 1946, e o modelo de Solow publicado em 1959. Todavia, na segunda, o crescimento é condição necessária mas não suficiente para o desenvolvimento. Nesta estão os economistas de orientação crítica, formados na tradição marxista ou cepalina, como, por exemplo, Raul Prebisch e Celso Furtado que realizaram análises e elaboraram modelos mais próximos da realidade das economias subdesenvolvidas, e estavam voltados para a realidade empírica. A corrente crítica conceitua o crescimento como uma simples variação quantitativa do produto, enquanto desenvolvimento é caracterizado por mudanças qualitativas no modo de vida das pessoas, nas instituições e nas estruturas produtivas (SOUZA, 1995).

De acordo com Oliveira (2002, p.40),

o desenvolvimento deve ser encarado como um processo complexo de mudanças e transformações de ordem econômica, política e, principalmente, humana e social. Desenvolvimento nada mais é que o crescimento - incrementos positivos no produto e na renda - transformado para satisfazer as mais diversificadas necessidades do ser humano, tais como: saúde, educação, habitação, transporte, alimentação, lazer, dentre outras (OLIVEIRA, 2002, p.40).

Souza (1995) define o desenvolvimento econômico pela existência de crescimento econômico contínuo, em ritmo superior ao crescimento demográfico, envolvendo mudanças estruturais e melhorias de indicadores econômicos e sociais. É compreendido, ainda conforme a autora, por um fenômeno de longo prazo, levando ao fortalecimento da economia nacional, a ampliação da economia de mercado e da produtividade. Outra abordagem é retratada por Amartya Sen (2000), na qual o desenvolvimento tem de estar relacionado, sobretudo, com a melhora da qualidade de vida.

O desenvolvimento não se dá de forma análoga em todos os lugares, ocorrendo em maior/menor escala de região para região. Segundo Hirschman (1961), isso acontece, devido à atuação de forças em pontos isolados desencadeando na concentração espacial.

Por tais razões, emerge o conceito de desenvolvimento regional, fruto da integração do fator espaço na teoria econômica. A agregação do espaço ao desenvolvimento ocasionou na comparação entre as regiões e a comprovação da necessidade de redução das desigualdades regionais por meio da recuperação daquelas mais atrasadas, categorizando o desenvolvimento regional como um procedimento de mudança da estrutura social (BEGNINI, 2014). Há de se destacar, que o estado de Minas Gerais é marcado pela existência de disparidades entre as suas regiões (ROSADO; ROSSATO; LIMA, 2009; COSTA et al. 2012).

Ainda segundo Begnini (2014), o desenvolvimento regional pode ser desmembrado em outros aspectos/características, como o desenvolvimento rural. A definição de desenvolvimento rural passou por mudanças no decorrer dos anos. Contudo, as significações têm em comum a ênfase na melhoria do bem-estar da população rural como elemento fundamental para esse desenvolvimento (NAVARRO, 2001). 
Oliveira e Lima (2003) argumentam, em termos regionais, que o desenvolvimento está relacionado à participação da população local no planejamento da ocupação do espaço e assim como na forma como são distribuídos os resultados do processo de crescimento. Moraes (2003), afirma que no ponto de vista do desenvolvimento regional deve-se considerar o território como um sistema que é influenciado por muitas variáveis.

Para Hirschman (1961), a função do governo no processo de desenvolvimento econômico está na promoção de infraestrutura social necessária para estimular a atividade produtiva (serviços públicos, infraestrutura logística, etc.) e no estabelecimento de estratégias de desenvolvimento, definindo as áreas/regiões prioritárias.

No Brasil, a discussão em torno do desenvolvimento rural tornou-se uma preocupação, sobretudo a partir da década de 1990, quando concentrou-se os esforços para o desenvolimento rural na agricultura familiar (ELLIS e BIGGS, 2001 apud CONTERATO, 2008). Além disso, houve a intensificação de políticas de combate à pobreza no campo, por meio do microcrédito rural, extensão de recursos previdenciários, entre outros (ELLIS; BIGGS, 2001 apud CONTERATO, 2008).

O desenvolvimento rural em nosso páis é interpretado como um conjunto de práticas que objetivam reduzir a vulnerabilidade dos agricultores familiares, de modo a torná-los independentes dos agentes externos, isto é, autônomos no sentido de serem capazes de tomarem decisões em suas ações e estratégias (CONTERATO et al., 2007).

As definições das várias vertentes do desenvolvimento (econômico, social cultural, sustentável, etc.) e desenvolvimento rural, no entanto, devem ser alvo de constantes estudos. Segundo Begnini (2014), são questões quase que inesgotáveis e para as quais dificilmente haverá uma única definição.

E, é devido a tais fatos que a solidificação do conceito de desenvolvimento como um processo de mudanças socioeconômicas deu origem ao desafio de mensurá-lo. Para tanto, fazse necessário a utilização de indicadores e de diferentes variáveis, de forma a compreender todos os aspectos que abarcam as condições de vida da sociedade (OLIVEIRA, 2014).

Segundo Orlowski e Arend (2005), em geral os aspectos considerados nestes indicadores são: saúde, nível educacional, renda, acesso a bens públicos, produtividade do trabalho, crescimento populacional, urbanização, lazer e longevidade, por exemplo.

Uma das formas de se mensurar o desenvolvimento rural é por meio da construção de indicadores e índices. Este artifício, alvo de outros estudos, auxilia no conhecimento das realidades rurais, na síntese de informações importantes para a compreensão dos pontos potencias assim como aqueles que ainda estão incipientes, norteando onde o governo deverá atuar. Portanto, na próxima seção dedica-se um espaço para discussão sobre o IDR. 


\section{1 ÍNDICE DE DESENVOLVIMENTO RURAL}

Para Siche et al. (2007) há uma confusão sobre a definição de índice e indicador, onde muitas vezes são equivocadamente usados como sinônimos. Ainda de acordo com os autores, a diferença está no fato de que o índice é o valor agregado final de todo um processo de cálculo onde se utilizam, de modo inclusivo, indicadores como variáveis que o compõem. Normalmente um indicador é utilizado como um pré-tratamento aos dados originais. O índice, no entanto, pode ser empregado como um instrumento de tomada de decisão e previsão.

O indicador é uma ferramenta que permite a medição de aspectos de algum conceito, fato, fenômeno ou um problema, tendo como objetivo principal “[...] traduzir de forma mensurável determinado aspecto de uma realidade dada (situação social) ou construída (ação de governo)" (BRASIL, 2007, p. 4).

Siche et al. (2007), entendem o termo índice como um valor numérico que representa a adequada interpretação da realidade de um sistema simples ou complexo (natural, econômico ou social), empregando, em seu cálculo, embasamentos científicos e metodologias apropriadas.

Segundo Jannuzzi (2005), no campo aplicado das políticas públicas, os indicadores sociais são medidas usuais que permitem operacionalizar um conceito abstrato ou uma demanda de interesse pragmático. Assim sendo, "os indicadores apontam, indicam, aproximam em termos operacionais as dimensões sociais de interesse definidas a partir de escolhas teóricas ou politicas realizadas anteriormente" (JANNUZZI, 2005, p. 138). Ainda segundo Jannuzi (2002),

[...] se bem empregados, os indicadores sociais podem enriquecer a interpretação empírica da realidade social e orientar de forma mais competente a análise, formulação e implementação de políticas sociais. Na negociação das prioridades sociais, esses indicadores podem contribuir no dimensionamento das carências a atender nas diversas áreas de intervenção (JANNUZZI, 2002, p.3)

Os indicadores proporcionam subsídios para as atividades de planejamento público e de formulação de políticas sociais nas distintas esferas do governo; permitem monitorar a qualidade de vida e o bem-estar da população, assim como o aprofundamento da investigação no meio acadêmico sobre a modificação social e sobre os determinantes dos diversos fenômenos sociais (MILLES, 1985 apud JANNUZZI, 2005; ONU, 1988).

De modo geral, conforme Kageyama (2004, p. 405), os pontos indispensáveis para obter medidas que apreendam a característica multidimensional do desenvolvimento, no caso específico do desenvolvimento rural, podem ser assim resumidos em,

(a) Escolher criteriosamente as dimensões do desenvolvimento que são consideradas essenciais; (b) Construir indicadores de cada dimensão que possam ser agregados para calcular a medida-síntese; (c) Definir as variáveis que serão combinadas para formar cada indicador; (d) Estabelecer critérios de ponderação para as variáveis ou indicadores (e) Definir a unidade territorial de observação (município, microrregião, mesorregião, etc.) (KAGEYAMA, 2004, p. 405).

DRd - Desenvolvimento Regional em debate (ISSNe 2237-9029) 
Pinto e Coronel (2014) argumentam que a construção de um índice de desenvolvimento rural baseia-se na percepção de que o desenvolvimento e suas consequentes desigualdades podem ser apreendidos por meio de simplificações a partir da construção de um índice.

Orsi (2009), no entanto, ao desenvolver o Índice de Desenvolvimento Comunitário Rural (IDCR), teve como objeto de estudo a comunidade rural. Além disso, considerou-se o índice como um instrumento de empoderamento, na medida em que apoiou-se os atores empenhados com o processo de desenvolvimento e com a gestão social, subsidiando a feitura da avaliação dos resultados obtidos. O IDCR possui informações, métodos e objetivos com o intuito de empoderar os agricultores familiares. E, ainda segundo o autor, é necessário empoderar para dar continuação e sustentabilidade ao processo de desenvolvimento do meio rural por várias gerações.

Segundo Kageyama (2004), as distintas metodologias utilizadas e os aprimoramentos efetivados originam da necessidade de obter em maior profundidade as heterogeneidades e as trajetórias do desenvolvimento rural. Assim, não há na literatura uma única forma de se calcular o desenvolvimento rural. Entretanto, há o consenso de que essa questão possui caráter multidimensional (KAGEYAMA, 2004; CONTERATO; SCHNEIDER; WAQUIL, 2007; MELO; PARRÉ, 2007; STEGE, 2011; ORSI, 2009; WAQUIL et al., 2015).

\section{METODOLOGIA}

O estudo caracteriza-se como descritivo e explicativo. Diante da natureza do problema investigado, a pesquisa assume caráter quantitativo, uma vez que recorreu-se ao uso da quantificação dos dados coletados, e os tratou por meio de técnicas estatísticas e com base na linguagem matemática para descrever as causas de um fenômeno ou até mesmo as relações entre variáveis (RICHARDSON, 1999).

O público-alvo da pesquisa foi composto por agricultores familiares de Minas Gerais, que possuem notável importância na produção de alimentos e na economia estadual. Segundo o Censo Agropecuário 2006, dentre as unidades da federação com maior número de estabelecimentos familiares, Minas Gerais encontra-se em segundo lugar representando $10,0 \%$ do total de todo o país (IBGE, 2009).

Para o cálculo amostral, portanto, considerou-se como universo a população de agricultores familiares correspondente as mesorregiões Norte e Jequitinhonha, que corresponde a 293.135 (IBGE, 2009). Adotou-se nível de confiança de 95\% e erro amostral de $7 \%{ }^{5}$. Assim, ao aplicar tais dados na Equação 1, obteve-se o total da amostra de 196 indivíduos.

\footnotetext{
${ }^{5}$ A justificativa para adoção do erro amostral de 7\% tem como base o estudo de Moreira, Silveira, Motter (2014). De acordo com Selltiz et al. (1974), a variação entre resultados individuais, num instrumento de medida aplicado a um grupo de pessoas, decorre de certo número de fatores contribuintes. Parte da variação pode ser entendida como resultante de diferenças reais, entre os indivíduos, quanto à característica que está sendo medida; parte dela representa erros na mensuração. Assim, dado que o universo de indivíduos a serem abordados estarem associados à um conjunto de características específicas que os focalizem nos agricultores familiares, adotou-se um erro amostral de 7\%, considerando que não haverá prejuízos às análises estatísticas.
}

DRd - Desenvolvimento Regional em debate (ISSNe 2237-9029)

v. 6 , n. 1, p. 90-119, jan./jul. 2016. 


$$
\begin{gathered}
\mathrm{n}=\frac{\sigma^{2} \times \mathrm{p} \times \mathrm{q} \times \mathrm{n}}{\varepsilon^{2}(\mathrm{n}-1)+\left(\sigma^{2} \times \mathrm{p} \times \mathrm{q}\right)} \\
n=\frac{1,96^{2} \times 0,5 \times 0,5 \times 437.415}{0,07^{2}(437.415-1)+\left(1,96^{2} \times 0,5 \times 0,5\right)}=196
\end{gathered}
$$

$\mathrm{O}(\sigma)$ refere-se ao nível de confiança escolhido $-95 \%=1,96 ;(\mathrm{p})$ probabilidade de ocorrência do fenômeno - 0,5 ; (q) probabilidade de não ocorrência do fenômeno $-0,5$; $(\mathrm{N})$ população - 437.415; (ع) erro - 0,07.

O estudo in loco foi realizado no estado de Minas Gerais, estabelecendo como foco duas mesorregiões: Norte e Jequitinhonha ${ }^{6}$. A escolha destas regiões deveu-se ao fato de tais localidades revelarem-se com os menores indicadores socioeconômicos en nível estadual. A mesorregião Norte de Minas possui o maior percentual de agricultores familiares do estado, com $24,75 \%$ e o Jequitinhonha o quinto maior percentual, com 9,08\%. As regiões, quando somadas, abrigam 293.135 agricultores familiares (MINAS GERAIS, 2014).

Para definição dos municípios que foram visitados, teve-se como parâmetro a proporção da população rural de cada localidade. A questão da acessibilidade aos municípios também foi um parâmetro de seleção. Ademais, estabeleceu-se as localidades das quais os técnicos da Empresa de Assistência Técnica e Extensão Rural do Estado de Minas Gerais (EMATER-MG) prontificaram a acompanhar a equipe de pesquisa (Tabela 1).

Os dados de origem primária, foram obtidos com auxílio da survey. Como instrumento de pesquisa, adotou-se do questionário estruturado sob a forma de entrevista pessoal com questões de múltipla escolha que, segundo Santos (1999), trata-se de um procedimento útil, especialmente em estudos caracterizados exploratórios e descritivos.

Os dados de origem secundária utilizados para a caracterização das regiões em destaque foram coletados no Censo Agropecuário $2006^{7}$ e Instituto Brasileiro de Geografia e Estatística (IBGE).

No intuito de alcançar os objetivos propostos, o tratamento dos dados para a construção do IDR, baseou-se na metodologia proposta nos estudos de Buainain e Souza Filho (2001), Kageyama (2004; 2006), Melo e Parré (2007), Martins e Cândido (2008) e Orsi (2009), entretanto com as modificações discutidas adiante.

\footnotetext{
${ }^{6}$ Ressalta-se que a pesquisa de campo, para a coleta de dados, foi realizada durante a execução do projeto que deu origem ao presente estudo, "Avaliação de impacto do Pronaf B sobre a satisfação com a produção, renda e qualidade de vida em Municípios de Minas Gerais", financiado pelo CNPq (Conselho Nacional de Desenvolvimento Científico e Tecnológico), sendo que a primeira autora integrou o grupo de pesquisa como bolsista de iniciação científica.

${ }^{7}$ O Censo Agropecuário de 2006, foi o último censo agrícola desenvolvido pelo IBGE, não existindo outro mais recente.
} 
Construção e análise do índice de desenvolvimento rural para as Mesorregiões Norte e Jequitinhonha do Estado de Minas Gerais

Tabela 1 - Relação dos municípios selecionados para estudo

\begin{tabular}{ccc}
\hline Mesorregião & Município & Proporção da População Rural (\%) \\
\hline \multirow{3}{*}{ Jequitinhonha } & Diamantina & 12,70 \\
& Coronel Murta & 26,70 \\
& Comercinho & 57,25 \\
Novo Cruzeiro & 65,75 \\
\hline José Gonçalves de Minas & 75,01 \\
\hline Salinas & 21,60 \\
Brasília de Minas & 33,76 \\
Januária & 36,88 \\
Espinosa & 42,07 \\
Monte Azul & 43,54 \\
& Matias Cardoso & 48,53 \\
& Porteirinha & 48,61 \\
& Ibiracatu & 49,26 \\
& Campo Azul & 57,90 \\
& Japonvar & 63,24 \\
& Cônego Marinho & 73,03 \\
& São João das Missões & 79,12 \\
\hline
\end{tabular}

Fonte: Resultados da pesquisa

$\mathrm{Na}$ seleção dos indicadores que compuseram o IDR, considerou-se os seguintes atributos de acordo com o estudo desenvolvido por Kageyama (2004): (i) ser significativo e condizente com a realidade investigada; (ii) empregar variáveis mensuráveis; e (iii) ser objetivo e de fácil entendimento. Além desses critérios, o que condicionou a escolha dos indicadores, assim como suas respectivas variáveis, foi a disponibilidade dos dados coletados durante a pesquisa junto aos agricultores familiares.

Portanto, o compilado das variáveis utilizadas na construção do índice foram subdivididas em quatro dimenões, quais sejam: Social, Econômica, Ambiental e Apropriação Tecnológica (Quadro 1).

Quadro 1 - Dimensões que compõem o Índice de Desenvolvimento Rural

\begin{tabular}{|l|l|}
\hline \multicolumn{1}{|c|}{ Dimensão } & \multicolumn{1}{c|}{ Descrição } \\
\hline Social & $\begin{array}{l}\text { A dimensão agregou as variáveis vinculadas direta ou indiretamente ao bem estar e à moradia, } \\
\text { no acesso a serviços básicos de saúde e educacionais. }\end{array}$ \\
\hline Econômica & $\begin{array}{l}\text { Procurou-se destacar o rendimento agrícola e não agrícola dos agricultores familiares, a forma } \\
\text { de comercialização, a origem dos recursos e mão de obra. }\end{array}$ \\
\hline Ambiental & $\begin{array}{l}\text { A finalidade foi destacar variáveis relevantes ao Desenvolvimento Rural, no âmbito das } \\
\text { questões envolvendo a preservação ambiental. Optou-se por caracterizar de forma ampla as } \\
\text { condições de uso dos recursos naturais e suas implicações/consequências para as populações e } \\
\text { atividades econômicas e seus reflexos para o desenvolvimento. }\end{array}$ \\
\hline $\begin{array}{l}\text { Apropriação } \\
\text { Tecnológica }\end{array}$ & $\begin{array}{l}\text { Considerou-se os bens duráveis aos quais o agricultor familiar possui acesso, no intuito de } \\
\text { identificar o seu nível de desenvolvimento, além das tecnologias obtidas para auxilio nas } \\
\text { atividades do estabelecimento rural. }\end{array}$ \\
\hline
\end{tabular}

Fonte: elaboração própria. 
Assim como no trabalho de Waquil et al. (2015), o IDR foi desenvolvido a partir da coleta de dados primários junto aos agricultores familiares das mesoregiões Norte e Jequitinhonha, no estado de Minas Gerais, com aplicação de questionários com questões estruturadas. As respostas dos entrevistados refletem a percepção dos mesmos sobre as parâmetros analisados (social, econômica, ambiental e apropriação tecnológica), por meio das quais pretendeu-se abarcar características da multidimensionalidade do desenvolvimento.

Dessa forma, procedeu-se a construção dos indicadores parciais para posteriormente construir o IDR. O processo da construção do IDR seguiu a lógica apresentada por Moreira e Silveira (2015). Este procedimento está exposto na Figura 2.

Figura 1 - E emplo do procedimento para a construção de indicadores e índices.
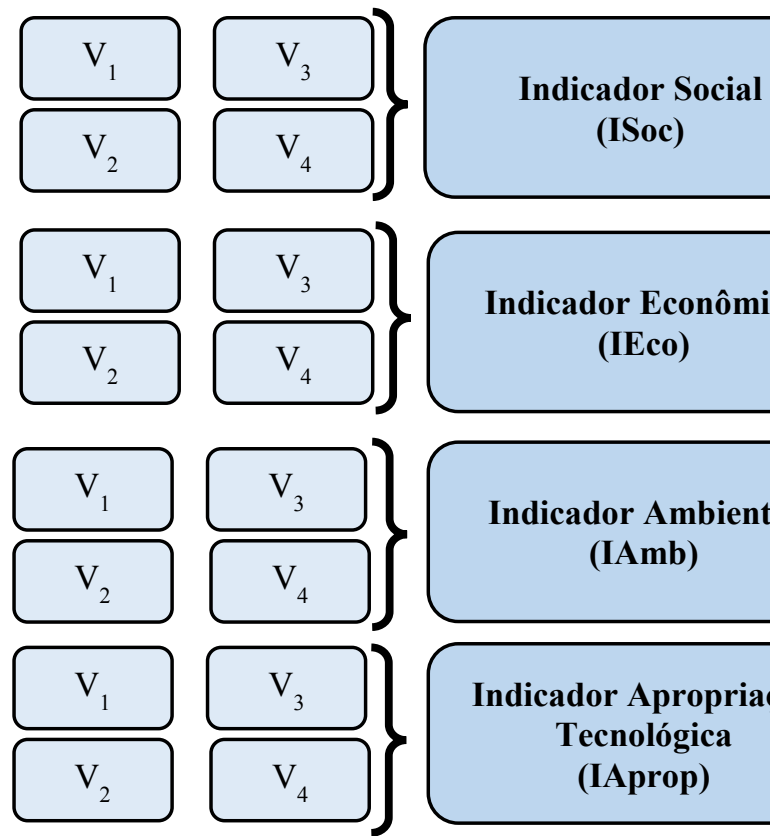

Indicador Econômico

(IEco)

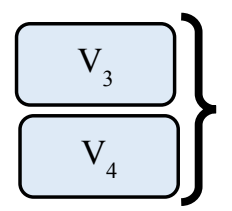

Indicador Ambiental

(IAmb)
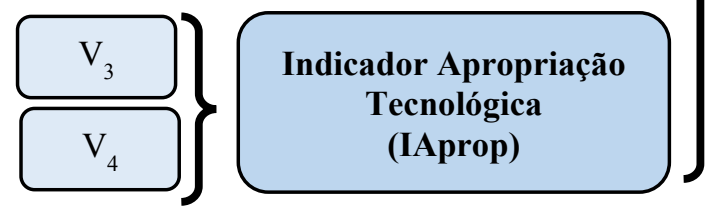

Etapa 1

Etapa 2

Etapa 3

Fonte: Adaptado de Moreira e Silveira (2015).

Cada dimensão possuí um conjunto de subdimensões compostas por suas respectivas variáveis. Como as variáveis possuem diferentes unidades de medida, foi necessária a transformação em números índices para permitir a agregação nas respectivas dimensões. Portanto, a etapa 1 consistiu em transformar as variáveis de cada subdimensão em escores cujos valores variassem entre zero (0) e um (1).

Essa transformação foi realizada com base na Equação 2. Esta metodologia é utilizada no cálculo do Índice de Desenvolvimento Humano (IDH) baseado nas indicações do Atlas de Desenvolvimento Humano no Brasil 2013 (PNUD, 2013). 


$$
I i=\frac{V i-P v}{\mathrm{Mv}-\mathrm{Pv}}
$$

Sendo (Ii) Indicador i; (Vi) Valor observado do indicador i; (Pv) Pior valor entre a distribuição do indicador i e (Mv) Melhor valor entre a distribuição do indicador i.

A Etapa 2, consistiu na construção dos indicadores. Por considerar que cada variável era importante para a mensuração do desenvolvimento rural dos agricultores familiares, atribui-se o mesmo peso para todas. Assim, obteve-se a média do conjunto de variáveis para formar cada subdimensão. E com a média das subdimensões, cada indicador foi calculado utilizando, novamente, a Equação 2.

A Etapa 3, compreendeu o estabelecimento do IDR. Deve-se primeiramente, escolher os pesos atribuídos a cada indicador integrante. No entanto, por não haver argumentos satisfatórios e consistentes que justificassem, por exemplo, que o indicador ambiental seja mais importante que a indicador econômico, optou-se por atribuir pesos iguais para todos os indicadores, para evitar vieses na análise do IDR (CONTERATO et al., 2007). Assim, como sugere Kageyama (2004), o cálculo do IDR foi a partir da média aritmética dos quatro indicadores parciais, conforme Equação 3.

$$
I D R=\frac{(I S o c+I E c o+I A m b+I A p r o p)}{4}
$$

Sendo, (IDR) Índice de Desenvolvimento Rural; (ISoc) Indicador Social; (IEco) Indicador Econômico; (IAmb) Indicador Ambiental; (IAprop) Indicador de Apropriação Tecnológica.

Após o cálculo da média dos quatro indicadores parciais, os valores encontrados foram outra vez modificados através da Equação 2 para se obter o índice final que variasse de 0 a 1 . Quanto mais próximo de 1, melhor o IDR. Assim, optou-se por classificar os níveis do IDR em quartis com base nos estratos indicados pelo Índice da Firjan de Desenvolvimento Municipal (IFDM) (Anexo I), quais sejam: $4^{\circ}$ quartil - alto desenvolvimento; $3^{\circ}$ quartil desenvolvimento moderado; $2^{\circ}$ quartil - desenvolvimento regular; e $1^{\circ}$ quartil - baixo desenvolvimento.

Os dados foram analisados por meio de procedimentos estatísticos manipulados nos programas Statistical Package for the Social Sciences (SPSS) v. 20.0® e MS Excel. Fez-se uso da estatística descritiva e da representação gráfica, gerando o diagrama de caixas (boxplot) e histogramas. 


\section{RESULTADOS E DISCUSSÕES}

\subsection{CENÁRIOS E CARACTERISTICAS DAS MESORREGIÕES ESTUDADAS}

As mesorregiões Norte de Minas e Jequitinhonha apresentam baixos indicadores socioeconômicos. Ambas possuem um dos menores Índices de Desenvolvimento Humano (IDH), 0,625 e 0,616, respectivamente, sendo que a média de Minas Gerais é de 0,667 , e estão entre as menores participações no Produto Interno Bruto (PIB) de todo o estado (4\% e $1 \%$, respectivamente) (PNUD, 2013). Na Figura 2, apresenta-se a localização das regiões em relação ao território estadual.

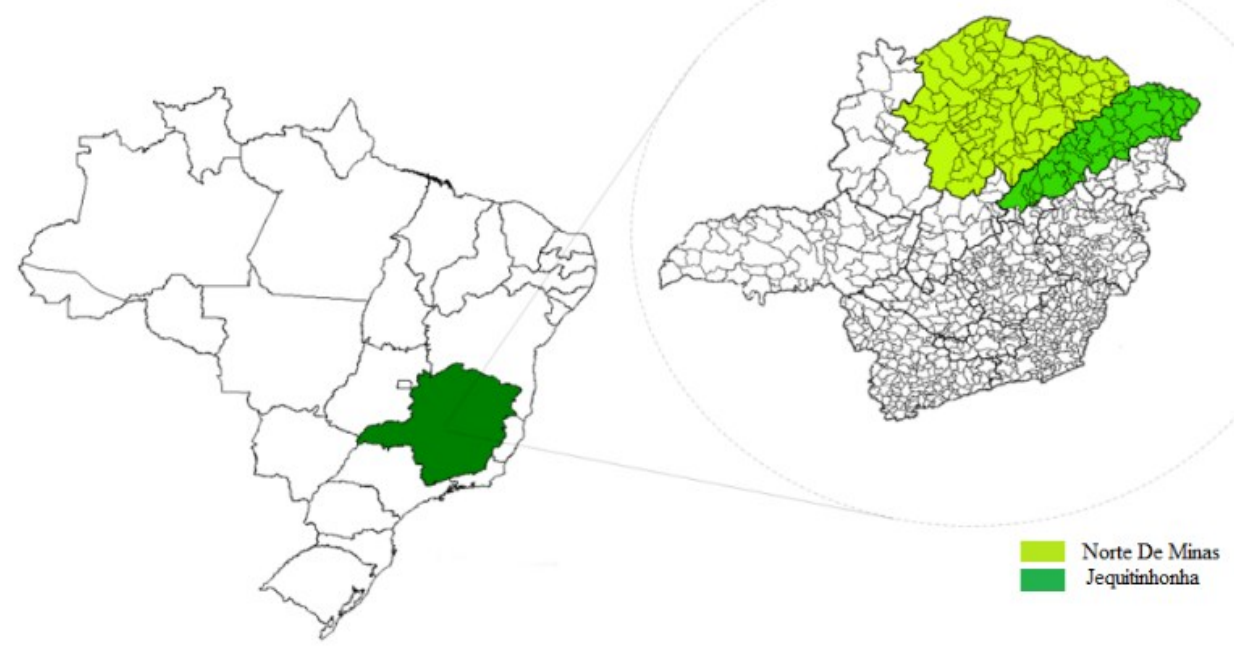

Fonte: elaboração própria.

O Jequitinhonha é uma região localizada no nordeste de Minas Gerais, banhada pelo Rio Jequitinhonha, composta 80 municípios que compreendem área de $85.467,10 \mathrm{~km}^{2}$, equivalente a 14,5\% do Estado, e população de 720.356 habitantes (IBGE, 2010), sendo que mais de $50 \%$ da população se encontra na área rural (IBGE, 2010). A mesorregião é subdividida em três regiões: Alto, Médio e Baixo Jequitinhonha (MEDEIRO, 2009).

O bioma que prevalece no Jequitinhonha é o da Mata Atlântica. No entanto, a vegetação é diversificada nas suas divisões regionais. No do Alto e Médio Jequitinhonha, as terras são mais altas, prevalecendo as chapadas tendo o cerrado como sua vegetação natural (MEDEIRO, 2009). No Baixo Jequitinhonha, as terras são baixas e com a temperatura elevada devido a diminuição da altitude. Predomina, nesta região, a savana como vegetação e encontra-se ampla plantação de capim colonião destinado à pecuária, principal atividade econômica da região (SOUZA, 1997). 
O Jequitinhonha é uma região heterogênea e possuidora de contrastes em sua população, nos costumes, na cultura e na economia (CARDOSO, 2007). A região passou por importantes ciclos econômicos, com ênfase na extração mineral e na produção algodoeira. Posteriormente com o declínio da mineração, surgiu na economia local a atividade pecuária, que conduziu a uma nova organização produtiva (CARDOSO, 2007).

Porém, as análises de estudos sobre a mesorregião, como os de Cardoso (2007) e Pereira (2007), tendem a inferir que as restrições em relação à questão hídrica e as secas prolongadas são os fatores determinantes para a baixa performance da agropecuária, principal atividade econômica regional.

O Norte de Minas, por sua vez, é composto por 89 municípios que compreendem área de $128.602 \mathrm{~km}^{2}$, equivalente a $22 \%$ do estado de Minas Gerais, com população de 1.610 .413 habitantes, sendo $69 \%$ urbana e $31 \%$ residindo no meio rural (IBGE, 2010).

Situada entre os biomas dos cerrados e a caatinga, a região é composta por áreas de cerrado $(63 \%)$, caatinga $(13 \%)$, mata seca $(7 \%)$, matas de transição $(14 \%)$ e de outras tipologias afins (3\%) (IFMG, 2008).

O clima semiárido do Norte de Minas é caracterizado pelas temperaturas elevadas e irregularidade das chuvas. Esta conjuntura tem influência no baixo padrão de vida da população, dada pela dificuldade da produção agrícola devido à seca.

Os estudos realizados na região, segundo Pereira (2007, p. 94) em sua maior parte estão relacionados "com a pobreza, a seca, a marginalização, o isolamento regional e a dependência dos municípios frente às transferências da união e do estado".

A mesorregião Norte de Minas é dividida em 7 microrregiões, sendo elas, Bocaiúva, Grão Mogol, Janaúba, Januária, Montes Claros, Pirapora e Salinas. A estrutura socioeconômica é concentrada, pois a pecuária extensiva e a agricultura relacionada ao agronegócio detém juntas a maior porção das terras (CARNEIRO FILHO, 2013).

Segundo Carneiro Filho (2013), nos cerrados há amplas áreas ocupadas com reflorestamento de eucalipto e a maior parte da população, sobrevive precariamente da agricultura de subsistência em pequenas unidades produtivas. Ressalta-se que há concentração, também, no fornecimento de água, levando a precárias condições de vida das pessoas que vivem nessa região. Afere-se que $67 \%$ das famílias rurais que fazem parte do semiárido não possuem acesso ao abastecimento de água (CARNEIRO FILHO, 2013).

Inserir um parágrafo de fechamento. "Portanto, uma vez conhecidas as características das mesorregiões em tela, realizou-se a seleção das variáveis e seus indicadores, tendo como base os atributos marcantes dos locais pesquisados". 


\subsection{SELEÇÃO DAS VARIÁVEIS E DOS INDICADORES}

Procurou-se um conjunto de variáveis que fossem complementares para expressar cada dimensão, de modo que juntas formassem um indicador. $\mathrm{O}$ primeiro indicador apresentado no Quadro 2, refere-se à dimensão social que, em consonância com Kageyama (2004), e Martins e Cândido (2008), leva-se em consideração três elementos: habitação, saúde e educação.

Para os atributos habitacionais, abordou-se a situação dos domicílios rurais, as condições em que se encontravam as moradias dos agricultores familiares. Na área da saúde, considerou-se a disponibilidade de serviços de saúde ao agricultor familiar e sua família, assim como condição da saúde da família e o número de doenças.

Estudos como os de Melo e Parré (2007) e Kageyama (2004), incluem a educação como importante indicador para expressar o desenvolvimento rural. Deste modo, buscou-se utilizar elementos como a existência de serviços educacionais, distância percorrida e a existência de transporte público para locomoção aos centros educacionais.

Quanto ao indicador econômico, foram consideradas variáveis relacionadas ao rendimento total anual da família, que envolve a renda proveniente do estabelecimento da agricultura familiar (agropecuária, produção animal e lavoura) e a renda não agropecuária (provenientes de benefícios sociais, aluguéis, dentre outros). Outro componente, diz respeito a origem da fonte de recursos relacionado ao financiamento da atividade desenvolvida no estabelecimento rural.

Buainain e Souza Filho (2001), em seu estudo, abordam o papel do crédito no desenvolvimento rural, alegando que a disponibilidade de recursos é uma das condições fundamentais para a produção agropecuária. O sistema de comercialização, também é relevante para expressar a situação econômica, como o local de comercialização, quem faz a comercialização.

Com o intuito de destacar variáveis relevantes para o desenvolvimento rural, no âmbito de questões relacionadas a preservação do meio ambiente criou-se o indicador ambiental, tendo como base o estudo de Orsi (2009).

O primeiro componente relacionado ao indicador ambiental refere-se à proporção de estabelecimentos que utilizam agrotóxicos. O uso indiscriminado de agrotóxicos e da mecanização está associada a possíveis danos ambientais. Dessa forma, espera-se que no âmbito das atividades exercidas pela agricultura familiar, o uso de agrotóxicos assim como de fertilizantes e adubos seja menos intenso. O segundo elemento, relaciona-se a conservação dos recursos naturais, que diz respeito ao plantio de árvore/leguminosas para fins de conservação de solo. O terceiro componente do indicador consiste na dotação de práticas de conservação do solo. A finalidade é verificar as condições e a preocupação dos agricultores em usar técnicas destinadas a esse fim, para garantir melhor adequação dos solos à atividade agrícola. A perspectiva é que as atividades ligadas à agricultura familiar apontem para um maior índice de conservação do solo.

O indicador de apropriação tecnológica foi fundamentado no estudo de Orsi (2009) que utilizou deste indicador para desenvolver o Índice de Desenvolvimento Comunitário 
Rural (IDCR). O indicador consiste nos recursos tecnológicos utilizados nas atividades desenvolvidas no estabelecimento rural, assim como nos aspectos ligados à assistência técnica. Além disso, mensura-sse acesso a bens duráveis, relacionando-o à qualidade de vida, como a aquisição de aparelhos elétrico-eletrônicos que facilitam as atividades domésticas e que proporcionam acesso ao lazer, e podem levar ao acesso à informação. Verificou-se, ainda, a existência de algum meio de transporte, seja moto, carro ou caminhão, que facilite a locomoção e transporte de produtos para comercialização.

Quadro 2: Indicadores que compõe o IDR e suas respectivas variáveis.

\begin{tabular}{|c|c|c|}
\hline Indicador & \multicolumn{2}{|r|}{ Variáveis } \\
\hline \multirow{3}{*}{ Social } & Habitação & $\begin{array}{l}\text { Condição do imóvel, material das paredes, material da } \\
\text { cobertura/teto, forma de iluminação, conservação da casa, forma de } \\
\text { escoamento do banheiro/sanitário, destino do lixo domiciliar. }\end{array}$ \\
\hline & Saúde & $\begin{array}{l}\text { Atendimento Médico, distância do atendimento, condição de saúde } \\
\text { da família, número de doenças na família. }\end{array}$ \\
\hline & Educação & 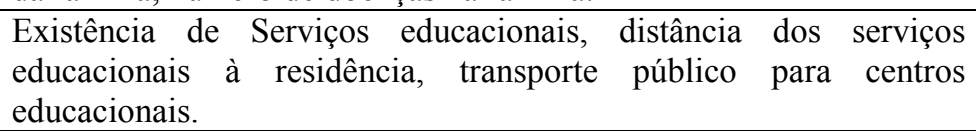 \\
\hline \multirow{3}{*}{ Econômico } & Nível de Renda & Rendimento total anual. \\
\hline & $\begin{array}{l}\text { Financiamento } \\
\text { da atividade }\end{array}$ & Origem da fonte de recursos. \\
\hline & $\begin{array}{c}\text { Sistema de } \\
\text { comercialização }\end{array}$ & Local de comercialização, quem realiza a comercialização. \\
\hline \multirow{3}{*}{ Ambiental } & $\begin{array}{l}\text { Uso e manejo de } \\
\text { agrotóxico }\end{array}$ & $\begin{array}{l}\text { Método de controle de praga utilizado, Intensidade do uso de } \\
\text { agrotóxico. }\end{array}$ \\
\hline & $\begin{array}{l}\text { Conservação dos } \\
\text { recursos naturais }\end{array}$ & Plantio de árvore/leguminosas para fins de conservação de solo. \\
\hline & Solo & $\begin{array}{l}\text { Destinos dos restos das culturas, rotação de cultura, uso de calagem, } \\
\text { adubação verde, uso de material orgânico, utilização de fogo nas } \\
\text { atividades agropecuárias. }\end{array}$ \\
\hline \multirow{4}{*}{$\begin{array}{l}\text { Apropriação } \\
\text { Tecnológica }\end{array}$} & Agricultura & $\begin{array}{l}\text { Irrigação, tipo de irrigação, uso de sementes melhoradas, preparação } \\
\text { do solo, adubação do solo, análise do solo, conservação do solo, } \\
\text { trator, colheitadeira, plantadeira. }\end{array}$ \\
\hline & Pecuária & Tanque resfriador de leite, botijão de sêmen, ordenhadeira. \\
\hline & $\begin{array}{l}\text { Acesso a } \\
\text { Assistência } \\
\text { Técnica }\end{array}$ & $\begin{array}{l}\text { Se há assistência técnica, quem fornece a assistência, frequência da } \\
\text { assistência técnica. }\end{array}$ \\
\hline & Bens Duráveis & $\begin{array}{l}\text { Geladeira/Freezer, televisão, aparelho de DVD, telefone fixo, } \\
\text { telefone celular, computador/notebook, acesso à internet, TV a } \\
\text { cabo, rádio, ferro de passar, fogão a gás, tanquinho, máquina de } \\
\text { lavar, aparelho de som, liquidificador, moto, carro, caminhão. }\end{array}$ \\
\hline
\end{tabular}

Fonte: Elaborado pelos autores, com base nos estudos de Buainain e Souza Filho (2001); Kageyama (2004); Melo e Parré (2007); Martins e Cândido (2008); Orsi (2009).

Uma vez identificada a base do Índice, na próxima seção apresenta-se o IDR e os indicadores que o compuseram, assim como a descrição e análise dos principais resultados obtidos. 


\section{3 ÍNDICE DE DESENVOLVIMENTO RURAL: APRESENTAÇÃO E O DIAGNÓSTICO DOS RESULTADOS}

Após a seleção das variáveis e do estabelecimenti dos indicadores componentes do IDR, esta seção direciona-se à descrever a construção do Índice que sintetiza as dimensões estabelecidas para estudo e discutir os achados da pesquisa.

Destaca-se que a amostra do estudo correspondia a 196 indivíduos. Todavia, durante a pesquisa de campo conseguiu-se aferir as respostas de 216 agricultores familiares, sendo portanto, este o número de observações que foram analisadas.

$\mathrm{Na}$ Tabela 2 apresenta-se a análise descritiva do IDR, que varia entre 0 e 1, e dos indicadores componentes. Dentre os indicadores que integram o Índice, também com variação entre 0 e 1, a Apropiação Tecnológica apresentou a menor média $(0,41328)$, isto reflete a realidade, uma vez que os agricultores familiares apresentam baixo uso de tecnologia. Por outro lado, o Indicador Social apresentou a maior média $(0,54597)$, o que pode ser reflexo das políticas sociais e agrícolas voltadas a esse segmento que exercem influência na qualidade de vida e bem estar dos agricultores familiares.

Quanto a variabilidade, o Indicador Social apresentou o menor desvio padrão $(0,17939)$, ao contrário do Indicador Ambiental que dentre os indicadores que integraram o IDR, foi o que apresentou maior desvio padrão $(0,25250)$, ou seja, os valores mais dispersos em relação a média. Quanto a assimetria, nota-se que todos os indicadores são assimétricos, com destaque aos Indicadores Social e Econômico que apresentam assimetria a esquerda.

Sindelar et al. (2014) afirmam que a curtose além de indicar o "grau de achatamento" de uma curva de distribuição de frequências, busca indicar o grau de concentração de valores em torno do centro da distribuição. Ainda segundo Sindelar et al. (2014), o coeficiente de curtose $(\mathrm{k})$ pode ser interpretado da seguinte forma: se $\mathrm{K}=0,263$, a curva corresponde a uma distribuição de frequência mesocúrtica (apresenta grau de achatamento equivalente ao da curva padrão); se $\mathrm{K}>0,263$, a curva corresponde a uma distribuição de frequência platicúrtica (apresenta alto grau de achatamento, superior ao normal, sendo mais aberta); se $\mathrm{K}<0,263$, a curva corresponde a uma distribuição de frequência leptocúrtica (apresenta um alto grau de afilamento com uma curva mais fechada).

Assim, nota-se que o Indicador Econômico apresentou um grau de curtose $(0,65098)$ maior que o coeficiente de curtose $(0,263)$, isto implica que os valores estão mais destoados da média, com a curva de distribuição de frequência com alto grau de achatamento. Os demais indicadores apresentaram uma distribuição de frequência mais próximos a média, com alto grau de afilamento da curva. 
Construção e análise do índice de desenvolvimento rural para as Mesorregiões Norte e Jequitinhonha do Estado de Minas Gerais

Tabela 2: Análise descritiva dos indicadortes.

\begin{tabular}{lccccc}
\hline \multicolumn{1}{c}{ Análise Descritiva dos Indicadores } & IDR & Isoc & IEco & IAmb & Iaprop \\
\hline Média & 0,43714 & 0,54597 & 0,42507 & 0,45620 & 0,41328 \\
Mediana & 0,42588 & 0,54294 & 0,44423 & 0,41224 & 0,41459 \\
Desvio padrão & 0,18271 & 0,17939 & 0,19560 & 0,25250 & 0,24989 \\
Curtose & 0,22560 & 0,11835 & 0,65098 & $-0,88979$ & $-1,05998$ \\
Assimetria & 0,28243 & $-0,30363$ & $-0,23218$ & 0,40788 & 0,21846 \\
\hline
\end{tabular}

Fonte: Resultados da pesquisa.

Na Tabela 3 apresenta-se os intervalos dos indicadores, IDR e a classificação dos níveis de desenvolvimento. Ressalta-se que fez-se uso de um conjunto de cores, com base no estudo de Martins e Cândido (2008), que correspondem a uma escala que caracteriza visualmente os níveis de desenvolvimento.

Assim, o IDR com valores entre 0,0000 e 0,31421 foram representados pela cor vermelha e caracterizados com performance que revela um nível de desenvolvimento baixo; os valores entre 0,31422 e 0,42587 foram representados pela cor laranja e caracterizados com performance que revela um nível de desenvolvimento regular; os índices com valores entre 0,42588 e 0,54858 foram representados pela cor verde claro e caracterizados com performance que revela um nível de desenvolvimento moderado; e por último, os valores entre 0,54859 a 1 foram representados pela cor verde escura e caracterizados com performance que revela nível de desenvolvimento alto.

Tabela 3: Intervalos dos indicadores, IDR e a classificação dos níveis de desenvolvimento

\begin{tabular}{|c|c|c|c|c|c|c|}
\hline Quartil & Classificação & IDR & ISoc & IEco & IAmb & IAprop \\
\hline $1^{\mathrm{o}}$ & Baixo & $\begin{array}{c}0 \mathrm{a} \\
0,31421\end{array}$ & $\begin{array}{c}0 \mathrm{a} \\
0,43917\end{array}$ & $\begin{array}{c}0 \mathrm{a} \\
0,39693\end{array}$ & $\begin{array}{c}0 \mathrm{a} \\
0,24897\end{array}$ & $\begin{array}{c}0 \mathrm{a} \\
0,19242\end{array}$ \\
\hline $2^{o}$ & Regular & $\begin{array}{c}0,31422 \mathrm{a} \\
0,42587\end{array}$ & $\begin{array}{c}0,43918 \mathrm{a} \\
0,54294\end{array}$ & $\begin{array}{c}0,39694 \mathrm{a} \\
0,44422\end{array}$ & $\begin{array}{c}0,24898 \mathrm{a} \\
0,41224\end{array}$ & $\begin{array}{c}0,19243 \mathrm{a} \\
0,41557\end{array}$ \\
\hline $3^{\circ}$ & Moderado & $\begin{array}{c}0,42588 \mathrm{a} \\
0,54858\end{array}$ & $\begin{array}{c}0,54295 \mathrm{a} \\
0,67963\end{array}$ & $\begin{array}{c}0,44423 \mathrm{a} \\
0,51600\end{array}$ & $\begin{array}{c}0,41225 \mathrm{a} \\
0,66530\end{array}$ & $\begin{array}{c}0,41558 \mathrm{a} \\
0,61790\end{array}$ \\
\hline $4^{\circ}$ & Alto & 0,54859 a 1 & 0,67964 a 1 & 0,51601 a 1 & 0,66531 a 1 & 0,61791 a 1 \\
\hline
\end{tabular}

Fonte: Fesultados da pesquisa.

DRd - Desenvolvimento Regional em debate (ISSNe 2237-9029) 
Os resultados dos quatro indicadores que integraram o IDR estão apresentados na Tabela 3, sendo que os quartis foram definidos com base nas observações e no comportamento dos dados coletados. Além disso, é importante salientar que o quartil exprime aquilo que os dados representam. Assim, nota-se que há uma concentração dos dados em valores mais baixos, ou seja, devido ao comportamento médio dos dados, enquadra-se poucos indicadores em níveis mais elevados, e isto deve ser levado em consideração no momento da interpretação.

A Figura 5 expõe a representação gráfica do Indicador Social separado em quartis, sendo que o conjunto dos valores da amostra compreendidos entre o $1^{\circ}$ e o $3^{\circ}$ quartis, é representado por um retângulo com a mediana indicada por uma barra. Neste caso, a mediana é 0,54 , o que significa que $50 \%$ dos agricultores familiares apresentaram o Indicador Social no nível de baixo a regular. Dos outros $50 \%, 25 \%$ da amostra estão no nível moderado e somente o restante $(25 \%)$ se encontram no nível alto de desenvolvimento.

Às vezes surgem na amostra valores que se distinguem dos restantes por serem muito grandes ou muito pequenos sendo denominados de valores atípicos - os outliers. Os outliers são representados nos diagramas de caixa por asteriscos vermelhos.

No caso do Indicador Social, alguns valores estão muito pequenos, abaixo do limite inferior do boxplot, indicando a existência de um percentual baixo de agricultores familiares entrevistados em situação diferente da maioria da amostra.

Nota-se que o diagrama de caixas se mostra com leve assimetria a esquerda (assimetria negativa), ou seja, a amostra, no geral, está concentrada entre os quartis regular e moderado de desenvolvimento rural.

Figura 3 - Representação gráfica do Indicador Social

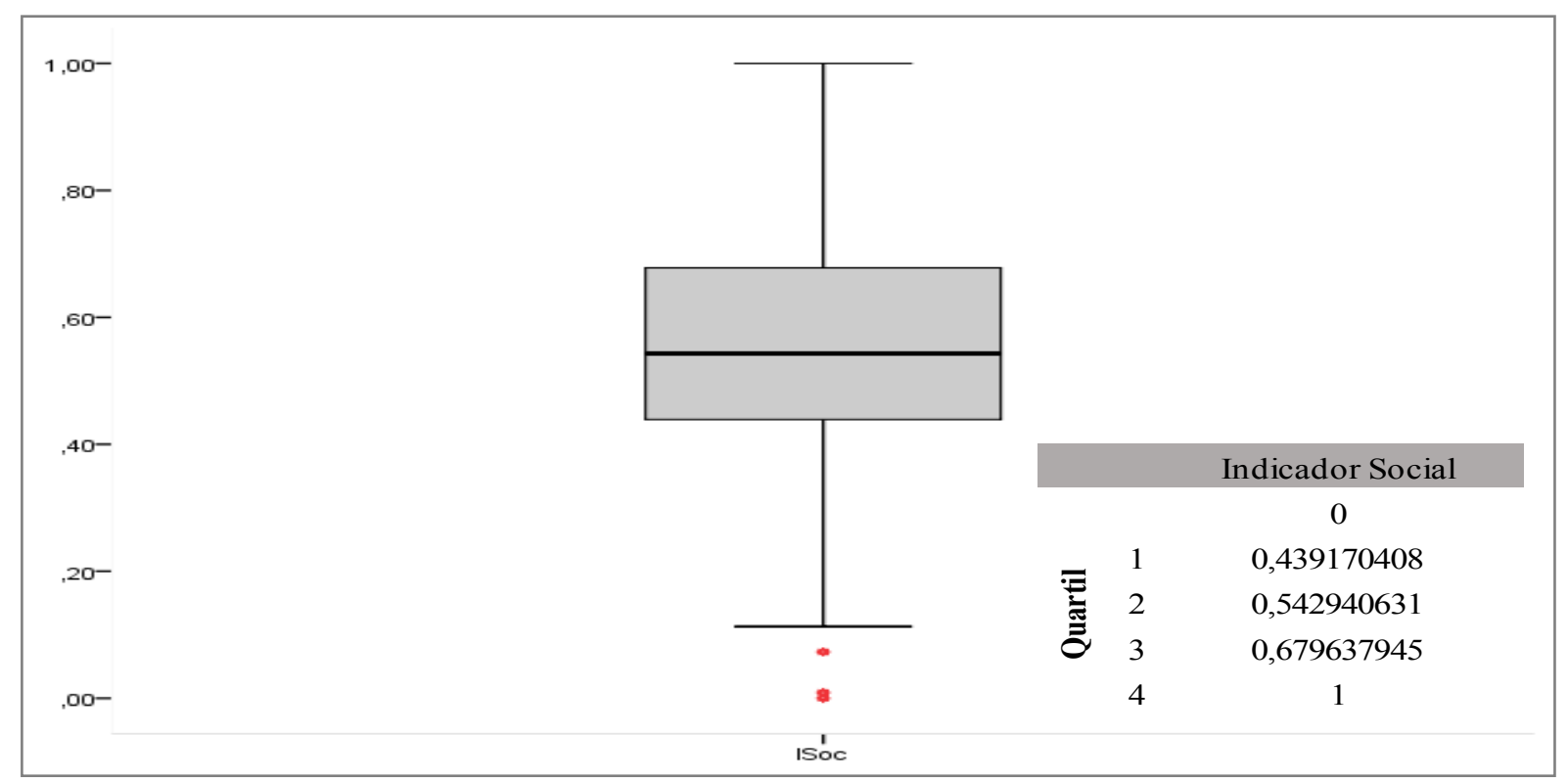

Fonte: Resultados da pesquisa. 
As variáveis associadas ao Indicador Ssocial foi bem avaliadas pelos agricultores familiares entrevistados, devido as intervenções do governo com intuito de combate à pobreza e promoção de desenvolvimento, fomentando às atividades rurais, seja por meio de políticas sociais, como por exemplo o Bolsa Familia, ou por políticas agrícolas com destaque para o Programa Nacional de Fortalecimento da Agricultura Familiar (PRONAF), o Programa de Aquisição de Alimentos (PAA), o Programa Nacional de Alimentação Escolar (PNAE) e ações como o Bolsa Estiagem e o Garantia Safra.

Empiricamente ficou claro que o efeito mais importante para os agricultores familiares entrevistados, foi a percepção de que passaram a viver melhor por meio das políticas sociais e agrícolas, o que pode ser traduzido em uma qualidade de vida melhor, alimentação com diversidade e quantidade suficiente para o atender as necessidades básicas das famílias.

Quanto ao Indicador Econômico, representado na Figura 4, nota-se que 75\% dos agricultores familiares entrevistados apresentaram resultados inferiores a 0,51 (terceiro quartil), ou seja, concentram-se nos níveis baixo a moderado, e apenas $25 \%$ estão localizados no nível alto.

Ao avaliar e comparar a variabilidade de conjunto de dados por meio do boxplot, deve-se observar a altura das caixas. No caso do Indicador Econômico nota-se que a altura da caixa é menor quando comparada à altura da caixa dos outros Indicadores que compõem o IDR, demonstrando a priori que embora a representação gráfica apresente uma tendência a homogeneidade, isto na verdade, é devido a presença de muitos outliers.

O diagrama de caixas do Indicador Econômico demonstra menor espaço entre a mediana e o limite inferior, sendo verificada forte concentração nos valores menores, o que demonstra uma distribuição assimétrica a esquerda.

Figura 4 - Representação gráfica do Indicador Econômico

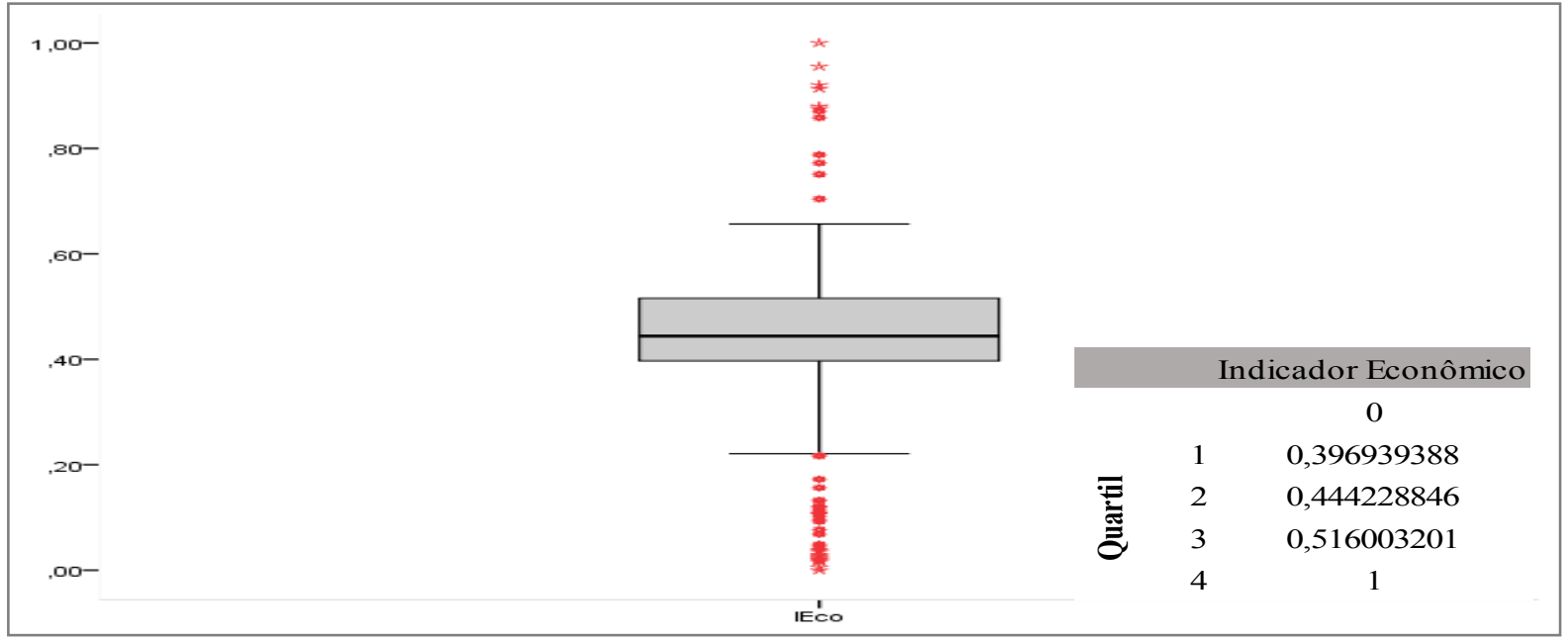

Fonte: Resultados da pesquisa. 
A existência de outliers pode indicar elementos que carecem de atenção especial, dependendo da análise é possível que justamente os outliers sejam os pontos de interesse. Ao examinar cada variável que compôs o Indicador Econômico, notou-se que a varíavel "redimento total anual" dos agricultores familiares entrevistados, que corresponde a soma da renda agropecuária e não agropecuária foi a que apresentou maior variabilidade. $\mathrm{O}$ desvio padrão $(5507,7)$ desta variável, em especial, representou aproximadamente $71 \%$ da média $(7758,3)$ da variável. Este fato, no entanto, pode ser uma das razões para o número expressivo de outliers tanto abaixo do limite inferior, quanto acima do limite superior.

Outro ponto a ser considerado são as dificuldades relacionadas ao clima da região, o tipo de solo, a ausência de recursos financeiros, que têm como consequência a baixa produção, restringindo a possibilidade de comercialização. Ligado a isso, as distâncias entre os empreendimentos rurais e os centros das cidades dificultam a participação dos agricultores em feiras livres ou em mercados municipais.

As poucas opções dos agricultores familiares diante das adversidades do clima devido a estiagens prolongadas - como relatadas pelos entrevistados que havia três meses sem chuvas -, e dos entraves da economia do semiárido do Norte de Minas fazem com que a produção transmita aspecto pouco dinâmico.

É muito comum a venda do excedente da produção entre vizinhos e comunidades rurais mais próximas, geralmente os preços praticados nessas trocas é baixo, dados os vínculos de amizade que influenciam nos descontos dos valores das mercadorias, conforme constatado nas entrevistas realizadas com os produtores rurais. Assim, esse é outro fator que pode ter influenciado no comportamento do Indicador Econômico.

Outra característica econômica dos agricultores familiares entrevistados é que a maioria recebe algum tipo de benefício social, com destaque ao Bolsa Família, que complementa a renda ou em alguns casos é a única fonte de renda das famílias.

No que se refere ao Indicador Ambiental, apresentado na Figura 5, deve-se observar o deslocamento da caixa em relação a linha do boxplot. Ressalta-se que a caixa contém $50 \%$ das observações, logo isso implica que o seu deslocamento na linha informa onde estão concentrados os dados. No caso do Indicador Ambiental, há assimetria à direita, o que significa que os dados estão concentrados no nível baixo a regular.

Nota-se que a altura da caixa é maior quando comparada à altura da caixa do Indicador Econômico, indicando que a distribuição dos dados é mais dispersa (heterogênea). Isto relaciona-se, segundo Kageyama (2004), ao fato de que atividades ligadas à agricultura familiar apresentam maior índice de conservação do solo, considerando o fato de que as monoculturas com uso elevado de mecanização podem causar maiores impactos ambientais.

A agricultura familiar, ao fazer uso de técnicas próprias para melhorar a produção, não está, na maioria dos casos, prejudicando o meio ambiente. Salienta-se que foi muito comum na fala dos entrevistados a doação, por parte de sindicatos e associações, de sementes para o plantio, o que tem a possibilidade de incrementar a produção.

Assim, quanto maior o Indicador Ambiental, menor a tendência de monocultura, tendendo a utilização de práticas de conservação do solo. As áreas com agricultura familiar 
tendem a apresentar maior diversificação nas atividades, para atender a sua demanda por alimentos para subsistência.

Figura 5 - Representação gráfica do Indicador Ambiental

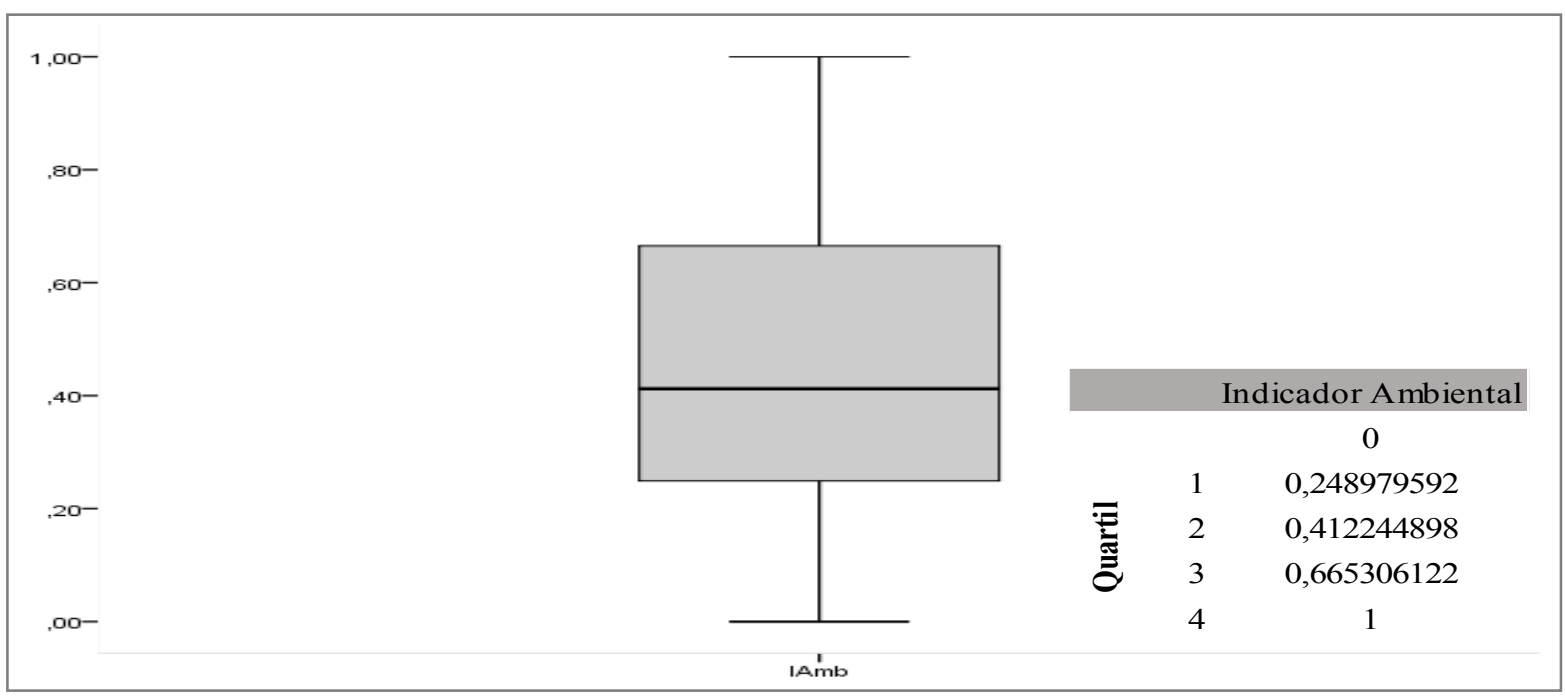

Fonte: Resultados da pesquisa.

O Indicador Apropriação Tecnológica, representado na Figura 6, apresentou os quartis com valores dispersos, dada a altura da caixa. A mediana é 0,41 , isto significa que $50 \%$ dos agricultores familiares estão concentrados nos níveis de baixo a regular desse indicador. Dos outros $50 \%, 25 \%$ estão localizados no nível moderado e apenas $25 \%$ estão no nível alto.

O diagrama de caixas possui uma leve assimetria para a direita (assimetria positiva), isto significa que os agricultores familiares concentram-se em níveis inferiores do Indicador Apropriação Tecnológica. Observou-se empiricamente, que a maioria do maquinário utilizado na condução do empreendimento rural é proveniente de aluguéis, refletindo a realidade dos agricultores familiares, devido ao baixo uso de tecnologias nas atividades agrícolas.

Figura 6 - Representação gráfica do Indicador Apropriação Tecnológica

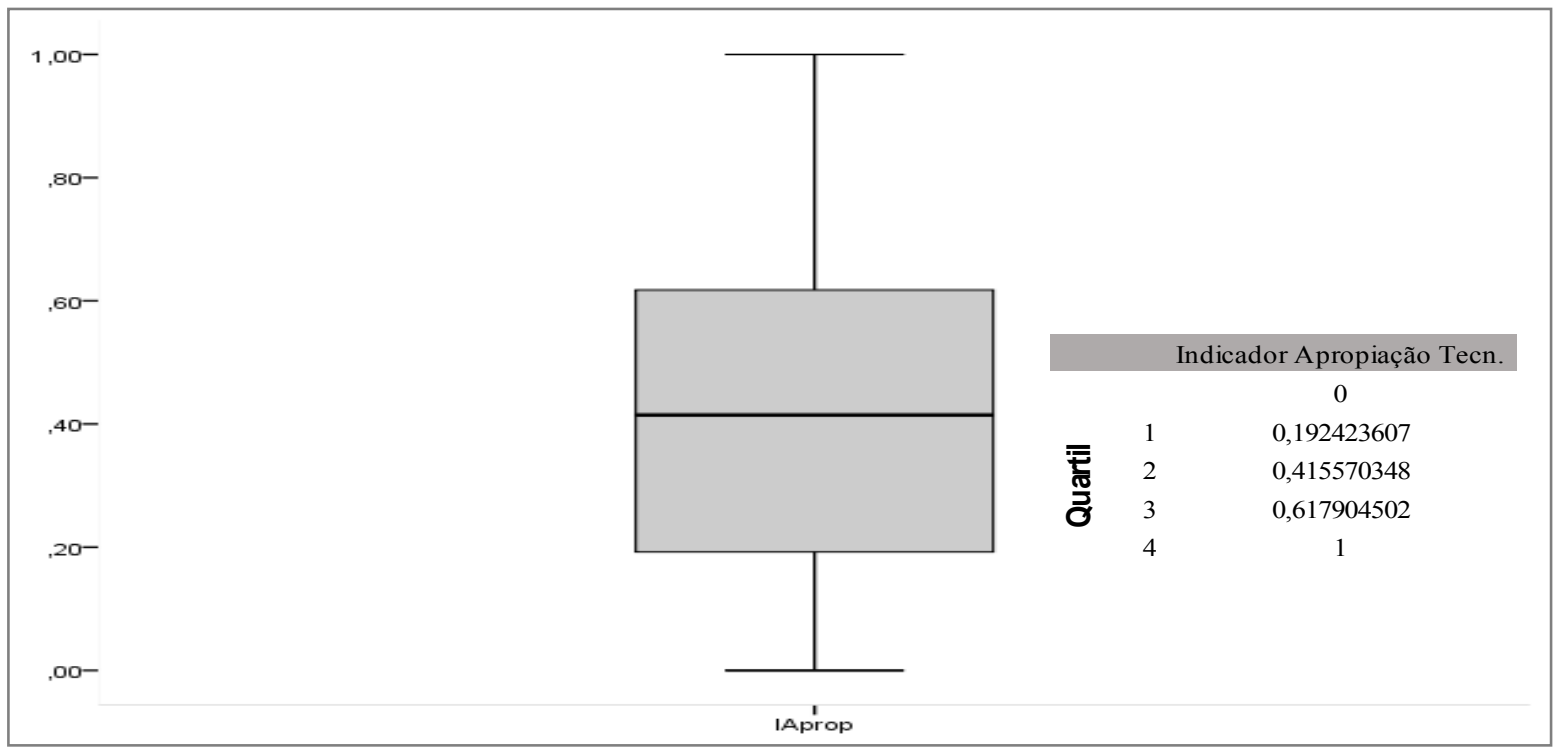

Fonte: Resultados da pesquisa.

DRd - Desenvolvimento Regional em debate (ISSNe 2237-9029) 
De posse dos indicadores anteriormente analisados foi possível construir o Índice de Desenvolvimento Rural,que está representado na Figura 7. Nota-se que 75\% dos agricultores familiares entrevistados encontram-se abaixo do terceiro quartil $(0,55)$, concentrando nos níveis de baixo a moderado, e apenas $25 \%$ estão no nível alto de desenvolvimento rural.

Percebe-se que a altura do diagrama de caixas do IDR é baixa, revelando ser um indicador com tendência à homogeneidade. O baixo número de outliers indica que existe baixo percentual de agricultores familiares entrevistados em situação diferente da maioria da amostra.

Figura 7 - Representação gráfica do Índice de Desenvolvimento Rural

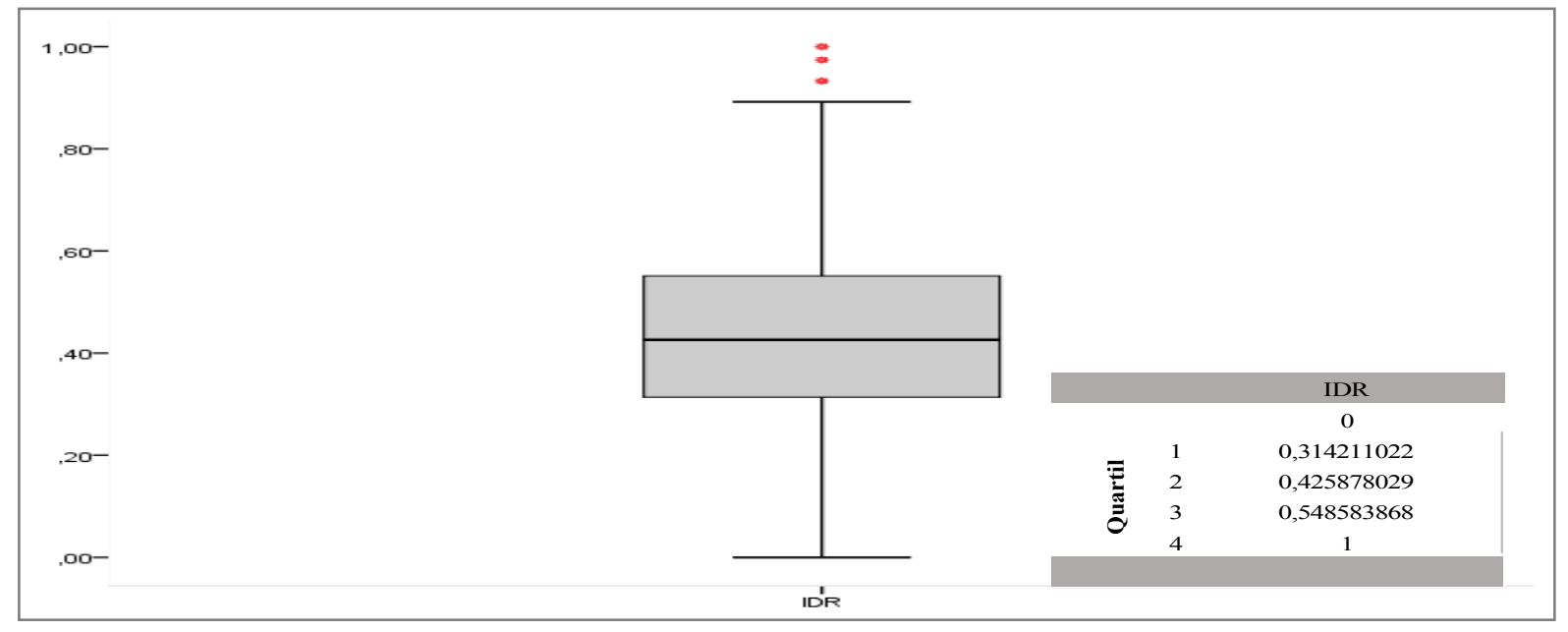

Fonte: Resultados da pesquisa.

O boxplot do IDR apresenta leve assimetria a direita e a caixa de tamanho pequeno o que evidencia forte concentração nos três primeiros quartis, os quais apontam para um nível baixo a moderado de desenvolvimento rural, e isto também pode ser notado no histograma ilustrado na Figura 8. 
Figura 8 - Histograma representando o Índice de Desenvolvimento Rural

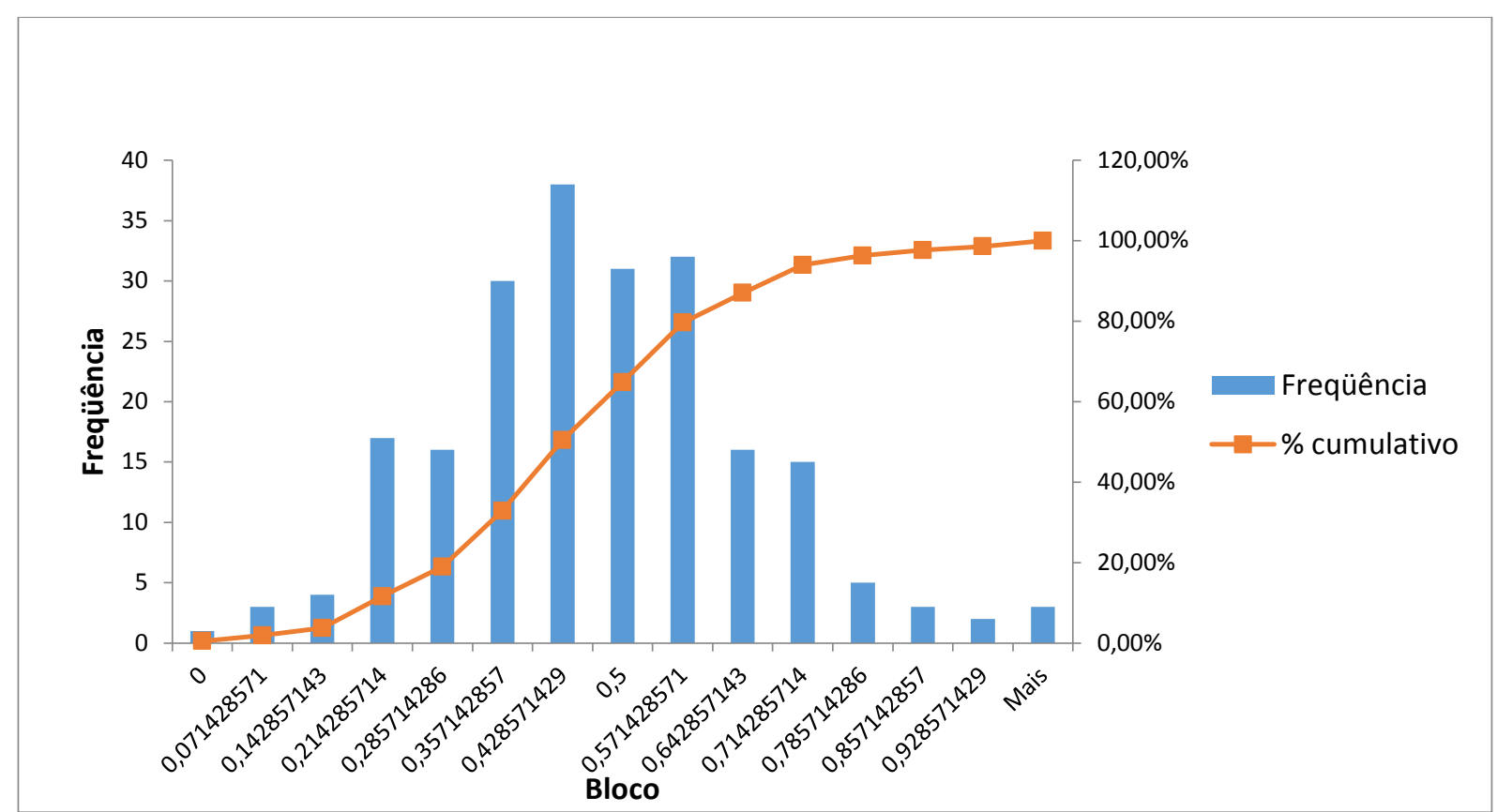

Fonte: Resultados da pesquisa.

De acordo com o estudo da Kageyama (2004), deve-se considerar três casos para a avaliação do desenvolvimento rural: (i) IDR com todos os elementos altos constitui desenvolvimento rural equilibrado em todos os seus aspectos; (ii) IDR com componentes baixos de modo uniforme significa a necessidade de implementar medidas em todas as extensões (econômico, social, ambiental e apropriação tecnológica), para melhorar a conjuntura; e (iii) IDR alto com elementos muito discrepantes significa um desenvolvimento desequilibrado e carente de alguma intervenção política.

Assim, nota-se que o IDR analisado neste estudo enquadra-se no segundo caso, sendo necessária a atuação do governo - seja em subsídios, incentivos, políticas públicas -, de modo a potencializar o desenvolvimento rural sustentável nas mesorregiões Norte de Minas e Jequitinhonha.

\section{CONCLUSÕES}

O estudo objetivou realizar uma análise empírica da medição do desenvolvimento rural, por meio da construção do IDR, aplicada nas mesorregiões Norte de Minas e Jequitinhonha. Os resultados obtidos permitem relevantes considerações referente as disparidades das condições em que o desenvolvimento rural se encontra as mesorregiões estudadas.

De modo geral, o IDR oscilou entre os níveis de desenvolvimento de baixo a moderado. Os indicadores que integraram-no concentraram-se em níveis baixos de maneira uniforme, assim, torna-se necessária a atuação do governo em todas as extensões analisadas 
(econômica, social, ambiental e apropriação tecnológica) para possibilitar que maior número de agricultores familiares alcance níveis de desenvolvimento rural mais alto.

No caso do Indicador Social, a maior parte dos agricultores familiares entrevistados estão concentrados entre os quartis regular e moderado de desenvolvimento rural. Apesar das intervenções do governo para o combate à pobreza, promoção de desenvolvimento e fomento das atividades rurais, é necessário que haja um maior empenho dos formuladores de políticas públicas, para avaliar se de fato as políticas sociais e agrícolas tem atendido os objetivos propostos, além dos anseios e necessidades desse segmento da população.

No que tange o Indicador Econômico, um aspecto observado na análise foi que a população rural dos municípios visitados possui, em sua maioria, baixa renda. E isto pode ser reforçado devido às condições socioeconômicas e climáticas das mesorregiões que contribuem para o alto número de agricultores familiares de baixa renda e em situação de pobreza. A evolução histórica marcada por desigualdades regionais, além da permanência de um modelo agrícola de produção de subsistência, interferiram no desenvolvimento rural das mesorregiões.

Dentre os indicadores que compuseram o IDR, o Indicador Ambiental foi o que apresentou maior dispersão dos dados em torno da média. Isto relaciona-se ao fato de que os agricultores familiares em geral e particularmente nas regiões estudadas, utilizam técnicas rudimentares de produção. Isso não significa necessariamente que estejam agindo sem causar danos ao meio ambiente, às vezes até ao contrário, ao fazer uso das queimadas, pastagens degradadas, entre outras ações, podem ter reflexos danosos ao meio ambiente e são comuns nas regiões. Muitas vezes também não são adotadas técnicas corretas de adubação e correção de solo, que acabam exaurindo os recursos e prejudicando o solo.

O Indicador Apropriação Tecnológica figurou-se entre os níveis baixo e regular, o que reflete a realidade dos agricultores familiares das mesorregiões estudadas, que demonstraram pouco uso de tecnologias nas atividades agrícolas e a baixa mecanização no campo.

É relevante mencionar que nos municípios visitadas havia associações de produtores rurais que, além de desempenhar seu papel na comunidade, faziam parte também do Conselho Municipal de Desenvolvimento Rural Sustentável (CMDRS). Isso indica um importante instrumento de debate no meio rural sobre suas necessidades frente ao poder público local.

O conhecimento de tais peculiaridades gera informações para a formulação/aperfeiçoamento de políticas públicas visando promover o desenvolvimento dessas mesorregiões.

Ressalta-se, que estudos como este, apresentam potencial de expor elementos característicos das regiões estudadas e que os formuladores e executores de programas destinados aos agricultores familiares poderiam considerar, para definir as ações estratégicas, além de como e onde priorizar os investimento e os subsídios.

Para a medição do desenvolvimento rural é necessário considerar vários temas relacionados a área, exigindo seleção criteriosa de variáveis e a combinação dessas em cada dimensão. 
O uso de dados primários exige maiores esforços dos pesquisadores e pode ser visto como uma limitação, entretanto, a sua obtenção por meio de questionários torna-se mais simples. Esse estudo permitiu constatar a possibilidade de se trabalhar com fontes primárias, além de identificar a possibilidade de atualização do IDR. Outro aspecto positivo é o fato de serem o próprios produtores rurais que apresentam as suas percepções sobre o nível desenvolvimento rural que alcançaram. Além disso, foi possível constatar que os resultados obtidos são consistentes com os resultados de outros estudos que demonstram o baixo nível de desenvolvimento rural nas regiões estudadas. Sugere-se que estudos avaliativos como esse sejam ampliados para outras mesorregiões do estado de Minas Gerais, para que se possa ter um panorama do desenvolvimento rural mineiro e gerar contribuições para o planejamento e a elaboração de políticas públicas.

\section{REFERÊNCIAS}

ARRUDA, C. S.. Índice de Desenvolvimento Sustentável e Agronegócio nos municípios do Estado de Goiás: uma análise multivariada. Dissertação (Mestrado na Escola de Agronomia e Engenharia de Alimentos), Universidade Federal de Goiás. Goiânia, 2010.

BEGNINI, S. Desenvolvimento Rural: os municípios e as mesorregiões catarinenses. In: VIII ECC - Encontro de Economia Catarinense - Desenvolvimento Rural. Anais... Rio Grande do Sul, v. 01. p. 24-25. 2014.

BRASIL, ONU reforça a importância da agricultura familiar. In.: Portal Brasil. Disponível em: $\leq$ http://www.brasil.gov.br/economia-e-emprego/2014/10/onu-reforca-aimportancia-da-agricultura-familiar> Acesso em: 17 abr. 2015.

BRASIL. Ministério do Desenvolvimento Agrário. Agricultura Familiar no Brasil e o Censo Agropecuária 2006. Brasília, 2009.

BRASIL. Ministério do Desenvolvimento Agrário. Brasília: MDA, 2013. Disponível em: <www.mda.gov.br>. Acesso em: 17 abr. 2015.

BRASIL. Ministério do Planejamento, Orçamento e Gestão. Secretaria de Planejamento e Investimentos Estratégicos. Uso e Construção de Indicadores no PPA. Brasília, 2007. Disponível em: <www.seplan.se.gov.br/modules/wfdownloads/visit.php?cid=1\&lid=303>. Acesso em: 23 abr. 2015.

BUAINAIN, A M. e SOUZA FILHO, H.M. Elementos para análise e desenho de políticas de crédito para agricultura familiar. NEA, IE/UNICAMP. São Carlos, 2001.

CANODÁ, L. A. Índice de Desenvolvimento Rural Sustentável. Tese (Doutorado na Escola Superior de Agricultura "Luiz de Queiroz"), Universidade de São Paulo. Piracicaba, 2013. 
CARDOSO, D. Recursos naturais, unidades de conservação e conflitos socioambientais: estudos de caso da reserva biológica da mata escura no Vale do Jequitinhonha, Minas Gerais. Dissertação (Mestrado em Programa de Pós-Graduação em Desenvolvimento Rural), Universidade Federal do Rio grande do Sul. Porto Alegre, 2007.

CARNEIRO FILHO, J. Comparação dos Níveis de Privações entre Agricultores Familiares no Semiárido Norte-Mineiro frente aos Programas de Convivência e do Microcrédito Produtivo Rural. Tese (Doutorado no Programa de Pós-Graduação em Desenvolvimento Rural), Faculdade de Ciências Econômicas (UFRGS). Porto Alegre, 2013.

CONTERATO, M. A. Dinâmicas regionais do desenvolvimento rural e estilos de agricultura familiar: uma análise a partir do Rio Grande do Sul. 2008. Tese (Doutorado no Programa de Pós-Graduação em Desenvolvimento Rural), Universidade Federal do Rio Grande do Sul. Porto Alegre, 2008.

CONTERATO, M. A.; SCHNEIDER, S.; WAQUIL, P. D. Desenvolvimento rural no Estado do Rio Grande do Sul: uma análise multidimensional de suas desigualdades regionais.

REDES, Santa Cruz do Sul, v. 12, n. 2, p. 163-195. 2007.

COSTA, C. C. M.; FERREIRA, M. A. M.; BRAGA, M. J. ; ABRANTES, L. A. Disparidades Inter-regionais e Características dos Municípios de Minas Gerais. Desenvolvimento em Questão, v. 10, p. 52-88. 2012.

COSTA, D. S. M.; RUAS, K. F.; PEREIRA, A. M. As Potencialidades da Região Semiárida do Norte de Minas Gerais: Análise do Centro de Estudos de Convivência com o Semiárido. In.: XVI Encontro Nacional dos Geógrafos, Crises, práxis e autonomia: espaços da resistência e de esperanças. Anais... Porto Alegre, 2010.

HELFAND, S. The political economy of agricultural policy in Brazil: decision-making and influence from 1964 to 1992. Latin American Research Review, v. 34, n. 2, p. 3-41, 1999.

HIRSCHMAN, A. O. Estratégia do desenvolvimento econômico. Rio de Janeiro: Fundo de Cultura Econômica, 1961.

IBGE. Censo Demográfico do Brasil 2010. Resultados Preliminares. Disponível em: $<$ http://www.ibge.gov.br>. Acesso em: 30 set. 2015.

IFDM - Índice Firjan de Desenvolvimento Municipal. Disponível em: $<$ http://www.firjan.com.br/ifdm/>. Acesso em: 25 nov. 2015.

IFMG - Inventário Florestal de Minas Gerais. Espécies Arbóreas da Flora Nativa. Lavras: UFLA, 2008.

INSTITUTO DO IMPLANTE. Mapa das Mesorregiões do Estado de Minas Gerais Principais cidades. Disponível em: $<$ http://www.institutodoimplante.com.br/profissionais_arquivos/ mapa_mesorregiao_mg.jpg >. Acesso em: 23 nov. 2015.

JANNUZZI, P. de M. Considerações sobre o uso, mau uso e abuso dos indicadores sociais na formulação e avaliação de políticas públicas municipais. RAP. Rio de Janeiro v. 36, n. 1. p. 51-72. 2002. 
JANNUZZI, P. de M.. Indicadores para diagnóstico, monitoramento e avaliação de programas sociais no Brasil. Revista do Serviço Público. Brasília, v. 56, n. 2, p. 137-160. 2005.

KAGEYAMA, A. Desenvolvimento Rural: conceito e medida. Cadernos de Ciência \& Tecnologia, Brasília, v. 21, n. 3, p. 379-408. 2004.

KAGEYAMA. A Produtividade e renda na agricultura familiar: efeitos do PRONAF crédito. Agricultura em São Paulo, São Paulo: IEA, v. 50, n. 2, p. 1-13. 2003.

KAGEYAMA. Desenvolvimento Rural no RS. In: SCHNEIDER, S. (Org.). A diversidade da agricultura familiar. Porto Alegre: Ed. Universidade/UFRGS, 2006.

KAGEYAMA. Desenvolvimento rural: conceitos e aplicações ao caso brasileiro. Porto Alegre: Editora da UFRGS, 2008.

KAGEYAMA. O novo padrão agrícola brasileiro: do complexo rural aos complexos agroindustriais. In: DELGADO, G; GASQUEZ, J.G.; VILLA VERDE C.M. (orgs). Agricultura e políticas públicas. 2.ed. Brasília: IPEA, 1996.

MALUF, L. A. F. F.; MATTEI, L.; LINS, H. N. Contribuição aos estudos sobre desenvolvimento socioeconômico em Santa Catarina: comportamento do IDS entre $1991 \mathrm{e}$ 2000. Textos de Economia. Florianópolis, v.9, n.1, p.91-117, 2006.

MARTINS, M. F.; CÂNDIDO, G. A. Índice de Desenvolvimento Sustentável - IDS dos Estados brasileiros e dos municípios da Paraíba. Campina Grande: Sebrae, 2008.

MEDEIRO, G. Vale do Jequitinhonha: a região e seus contrastes. Revista Discente Expressões Geográficas. Florianópolis, a. 5, n. 05, p. 81-100. 2009.

MELO, C. O. de.; PARRÉ, J. L. Índice de desenvolvimento rural dos municípios paranaenses: determinantes e hierarquização. Revista de Economia e Sociologia Rural. Brasília,v.45, n. 2, p. 329-365. 2007.

MINAS GERAIS. Perfil da agricultura familiar de Minas Gerais. Governo do Estado de Minas Gerais e Empresa de Assistência Técnica e Extensão Rural de Minas Gerais, 2014.

MORAES, J. L. A. Capital e políticas públicas para o desenvolvimento regional sustentável. Revista do Centro de Ciências Administrativas. v.9, n.2, p.196-204. 2003.

MOREIRA, V. de S.; SILVEIRA, S. de F. R.. Indicadores de desempenho do Programa Minha Casa, Minha Vida: avaliação com base na satisfação dos beneficiários. Cadernos Gestão Pública e Cidadania. São Paulo, v. 20, n. 66, p. 94-117. 2015.

MOREIRA, V. de S.; SILVEIRA, S. de F. R.; MOTTER, K. Z.. Avaliação de impacto do Pronaf B sobre a satisfação de agricultores familiares em municípios de Minas Gerais.

Revista Estudo Sociologia e Agricultura. Rio de Janeiro, v. 22, n. 2, p. 432-456. 2014.

NAVARRO, Z. Desenvolvimento rural no Brasil: os limites do passado e os caminhos do futuro. Estudos Avançados, v. 15, n. 43, p. 83-100. 2001. 
NORONHA, E. G.; TURCHI, L. Política industrial e ambiente institucional na análise de arranjos produtivos locais. Texto para discussão, Brasília, n. 1076. 2005. Disponível em: $<$ http://www.ipea.gov.br/agencia/images/stories/PDFs/TDs/td_1076.pdf $>$ Acesso em: 30 nov. 2015.

OLIVEIRA, G. B. de. Uma discussão sobre o conceito de desenvolvimento. Revista FAE. Curitiba, v.5, n. 2, p. 37-48. 2002.

OLIVEIRA, G. B.; LIMA, J. E. S. Elementos endógenos do desenvolvimento regional: considerações sobre o papel da sociedade local no processo de desenvolvimento sustentável. Revista da FAE. Curitiba, v.6, 2003.

OLIVEIRA, M. de J. Recursos compensatórios hidrelétricos: avaliação do impacto sobre o desenvolvimento socioeconômico de municípios de Minas Gerais. Dissertação (Mestrado em Administração). Universidade Federal de Viçosa, 2014.

ORLOWSKI, R. F.; AREND, S. C. Indicadores de Desenvolvimento Socioeconômico na região da AMOSC - Associação dos Municípios do Oeste de Santa Catarina. In:

CONGRESSO DA SOBER, 43, 2005, Ribeirão Preto. Anais... Ribeirão Preto: FEA/USP, 2005.

ORSI, S. D. IDCR: Um instrumento de empoderamento para apoiar o desenvolvimento do espaço rural. EMATER de Brasília, 2009.

PEREIRA, A. M.; SOARES, B. R.. Cidade e região: Relações entre Montes Claros e as pequenas cidades do Norte de Minas Gerais (BR). In: XI Encuentro de Geógrafos de América Latina. Anais... Bogotá, 2007.

PINTO, N. M; CORONEL, D. A.. O desenvolvimento rural no Brasil: uma análise das evidências empíricas. In: Observatorio de la Economía Latino Americana, Número 194, 2014. Disponível em: $<$ http://www.eumed.net/cursecon/ecolat/br/14/desenvolvimentorural.hmtl>. Acesso em: 26 maio 2015.

PNDU - Programa das Nações Unidas para o Desenvolvimento. Atlas do desenvolvimento humano no Brasil 2013. Disponível em: $<$ http:// www.pnud.org.br/atlas/>. Acesso em: 09 out. 2015.

RICHARDSON, R. J. Pesquisa social: métodos e técnicas. 3. ed. São Paulo: Atlas, 1999.

ROSADO, P. L.; ROSSATO, M. V.; LIMA, J. E. Análise do desenvolvimento socioeconômico das microrregiões de Minas Gerais. Revista Econômica do Nordeste, v. 40, n.2, p. 297-309. 2009.

SANTOS, A. R. Metodologia científica: a construção do conhecimento. Rio de Janeiro: DP\&A, 1999.

SANTOS, G. R.; SILVA, R. dos S.. Os Irrigantes do Projeto Jaíba: da Produção de Subsistência à Agricultura Moderna. Cadernos do Desenvolvimento. v. 5, p. 349-372. 2010.

SEN, A. Desenvolvimento como liberdade. São Paulo: Companhia das Letras, 2000. 
SICHE, R. et al. Índices versus Indicadores: precisões conceituais na discussão da sustentabilidade de países. Ambiente \& Sociedade. Campinas, v. 1, n. 2. p. 137-148. 2007.

SILVA, E. A. et al. As regiões de planejamento de Minas Gerais sob a ótica do desenvolvimento rural sustentável: uma abordagem teórico-metodológica. Revista Adm. UFSM, v. 2, n. 2, p. 158-179. 2009.

SINDELAR, F. C. W.; CONTO, S. M. de; AHLERT, L.. Teoria e prática em estatística para cursos de graduação. 1. ed. Lajeado: Editora da Univates, 2014.

SOUSA, J. V. A.. Luzes e sombras sobre a história e a cultura do Vale do Jequitinhonha. In: SANTOS, G. R. (Org.). Trabalho, cultura e sociedade no norte/nordeste de Minas: considerações a partir das ciências sociais. Montes Claros/MG: Best Comunicação e Marketing, 1997.

SOUZA, N. de J. Desenvolvimento econômico. 5. ed. São Paulo: Atlas, 2005.

STEGE, A. L.. Desenvolvimento rural nas microrregiões do Brasil: um estudo multidimensional. Dissertação (Mestrado no Programa de Pós-Graduação em Ciências Econômicas), Universidade Estadual de Maringá. Maringá, 2011.

VEIGA, J. E. O Brasil rural precisa de uma estratégia de desenvolvimento. Ministério do Desenvolvimento Agrário (MDA), Núcleo de Estudos Agrários e Desenvolvimento Rural (NEAD). Texto para Discussão. Brasília, n. 1, 2001.

WAQUIL, P. et al. Indicadores sociais e desenvolvimento: interpretações a partir do Índice de Condições de Vida (ICV). In.:RADOMSKY, G. F. W.; CONTERATO, M. A.;

SCHNEIDER, S.. (Orgs). Pesquisa e desenvolvimento rural: técnicas, base de dados e estatística aplicada aos estudos rurais. Porto Alegre: Editora da UFRGS, 2015. v. 2.

Artigo recebido em: 08/02/2016

Artigo aprovado em: 02/04/2016 